Research Article

\title{
Theoretical and Numerical Investigation on Perforation Resistance of Monolithic and Segmented Concrete Targets with Steel Liners under Normal Penetration
}

\author{
Yi Cheng $\mathbb{D}^{1,2,3}$ Zhimin Xiao $\mathbb{D}^{1,2,3}$ and Yuan Zhang ${ }^{1,2,3}$ \\ ${ }^{1}$ College of Civil and Transportation Engineering, Hohai University, Nanjing 210098, China \\ ${ }^{2}$ Institute of Engineering Safety and Disaster Prevention, Hohai University, Nanjing 210098, China \\ ${ }^{3}$ Key Laboratory of Ministry of Education for Geomechanics and Embankment Engineering, Hohai University, \\ Nanjing 210098, China \\ Correspondence should be addressed to Yi Cheng; 1791880514@qq.com
}

Received 12 September 2019; Accepted 14 November 2019; Published 7 December 2019

Academic Editor: Valeria Vignali

Copyright (c) 2019 Yi Cheng et al. This is an open access article distributed under the Creative Commons Attribution License, which permits unrestricted use, distribution, and reproduction in any medium, provided the original work is properly cited.

\begin{abstract}
Steel-concrete composites are important armor protective materials with the increasing power of precision-guided weapons. In this study, the formula of residual velocity as well as the ratio between residual and initial kinetic energy $\left(E_{\mathrm{r}} / E_{0}\right)$ for concrete targets with a rear steel liner was derived. By establishing finite element models of steel liner concrete targets through ANSYS/LSDYNA, the effect of the steel liner layout on the perforation resistance was analyzed for both monolithic and segmented concrete targets, which were compared in terms of projectile kinematics characteristics, projectile energy consumption, and target damages. Four main conclusions were drawn: (1) a residual velocity prediction model of concrete targets with a rear steel liner was accurately proposed for the first time when velocity reduction coefficient $\eta$ was 0.15 and the derived $E_{\mathrm{r}} / E_{0}$ could be used to evaluate their corresponding perforation resistance; (2) moving back the steel liners enhanced the perforation resistance of both monolithic and segmented targets, but the performance of the latter was inferior to that of the former, which was reduced by $10 \%-16 \%$ under the same conditions; (3) during middle- and low-speed perforations, the projectile impact force was more influenced by the contact stiffness than the impact velocity; and (4) regarding the segmented targets, the perforation resistance of the 2nd target was better than the 1st target, which consumed about 10\%-20\% more projectile kinetic energy.
\end{abstract}

\section{Introduction}

In terms of military strikes and defense engineering, structure of walls should be thick in order to reduce the local damage effect [1-6] caused by projectile impacts, especially for structures requiring high-defense protection such as important fortifications and secret weapon storage sites; moreover, the employ space of such structures should be increased as well. A solution to this problem is using composite concrete walls [7-9] with a steel liner. They have not only a higher resistance but also a better ductility and integrity compared to reinforced concrete (RC) structures when attacked by weapons. Steel liner concrete structures are applied in engineering protection since they can effectively improve the perforation resistance of protective structures.
Based on transient dynamics and damage mechanics, many scholars have adopted several solutions to explore the perforation resistance of composite concrete structures with a steel liner, including theoretical model analysis, experimental research, engineering simulations, and computer algorithm development. Three aspects are mainly investigated:(1) the equivalent relationship between steel liners and concrete; (2) the analysis of residual and ballistic limit velocity (the minimum impact velocity of projectiles perforating targets) for penetrating these concrete structures; and (3) the influence of the steel liner layout on the perforation resistance of composite targets.

Many experts have deeply studied the equivalent relationship between steel liners and concrete, with remarkable achievements. Walter and Wolde-Tinsae [10] defined a 
thickness conversion formula between steel liners and concrete for RC targets with a rear steel liner, but it was applicable only to concrete in a specific strength range. Abdel-Kader and Fouda $[11,12]$ summarized and compared many empirical formulas of the ballistic limit velocity for perforating concrete and steel plates. They carried out 27 penetration tests with rigid projectiles perforating thin steel plates and concrete, which put forward the equivalent thickness conversion formula between steel plates and concrete. Based on the existing experimental data, Bruhl et al. [13] proposed a three-step design method for steelconcrete composite walls impacted by projectiles. Such composite walls exhibited $30 \%$ more perforation resistance than RC walls with the same thickness, and the method could be used to calculate their minimum steel plate thickness required for steel-concrete composite walls. Grisaro and Dancygier [14] developed a perforation resistance model for RC composite targets with a rear steel liner when impacted by rigid projectiles. This model could predict the reduction coefficient of concrete thickness for composite targets compared with RC targets and determine whether the structural design was reasonable according to the bullet resistance grades.

Residual or ballistic limit velocity analysis [15-18] is an important reference for weapon development, damage evaluation, and protection design. Many scholars have proposed a series of prediction models after long-term researches. As regards projectile residual velocity, Peng et al. $[19,20]$ conducted perforation tests on ultrahigh-performance steel fiber-reinforced concrete (UHP-SFRC) targets and derived a semianalytical model for the residual velocity of projectiles perforating concrete targets, achieving a high accuracy in the prediction of the residual velocity for segmented concrete targets with a rear steel liner. Chen et al. [21] carried out trajectory tests on thin steel plates; based on the principle of energy conservation, a new residual velocity prediction model for hemispherical projectiles perforating thin steel plates at a low speed was established. According to a modified energy theory and existing ballistic limit velocity formulas, Grisaro and Dancygier [22] adopted a semiempirical and semianalytical method to define a formula for predicting the residual velocity through concrete targets. In terms of projectile ballistic limit velocity, Barr [23] assumed that the rear steel liner was equivalent to the rear steel bars of targets and proposed a formula for predicting the projectile ballistic limit velocity in RC targets with a steel liner. Based on projectile perforation tests, Tsubota et al. [24] converted the steel liner into the equivalent concrete thickness and derived the ballistic limit velocity of projectiles perforating $\mathrm{RC}$ targets with a steel liner. Rosenberg and Dekel $[25,26]$ conducted several numerical simulations on projectiles perforating thick and thin metal plates; based on the results, they developed a simplified prediction model for projectile ballistic limit velocity, which was dependent on the target thickness.

As regards the influence of the steel liner layout on the perforation resistance of composite targets, Kojima [27] conducted 12 perforation tests on composite targets and found that adding steel liners on the back of the targets could better limit the projectile perforation and inhibit the fragmentation of the rear target surface. Remennikov and Kong [28] carried out impact tests on noncomposite steel plate-concrete-steel plate (SCS) samples, observing a higher impact resistance compared to RC plates. AbdelKader and Fouda [29] performed 26 penetration tests on concrete targets with a steel liner and confirmed the penetration resistance improvement by front or rear steel liners.

Unfortunately, the existing residual velocity prediction models for projectiles perforating concrete with a steel liner do not agree well with the experimental values because of neglecting the role of steel liners. On the contrary, many studies focused only on monolithic targets by analyzing the influence of the steel layout on their perforation resistance, while there are only a few antiperforation researches on segmented targets. Thus, the formula of residual velocity as well as the ratio between residual and initial kinetic energy $\left(E_{\mathrm{r}} / E_{0}\right)$ for concrete targets with a rear steel liner was deduced based on the conservation of kinetic energy. The validity of the residual velocity prediction model was verified using the experimental values reported by $\mathrm{Wu}$ et al. [30] and compared with the residual velocity formula they proposed. Then, by establishing finite element method (FEM) models of concrete targets with a steel liner through ANSYS/LSDYNA, partial penetration tests of Abdel-kader and Fouda [29] were simulated to analyze how the steel liner layout affected the perforation resistance of composite targets. Finally, these models were also improved for segmented concrete targets with a steel liner, which were analyzed similarly. In addition, the perforation resistance of these two types of concrete targets was compared in terms of projectile kinematics characteristics, projectile energy consumption, and target damages.

\section{Theoretical Investigation}

$E_{\mathrm{r}} / E_{0}$, which is the standard for evaluating the perforation resistance of concrete targets with a steel liner, is deduced according to the following assumptions: (1) the projectile is rigid and has no mass loss, which means that no or few deformations occur during the perforation; (2) targets are penetrated by the projectile vertically without inclination or attack angle; (3) the projectile, concrete, and steel liners are all continuous, uniform, and isotropic materials; (4) the gravitational potential energy, the internal energy, and the strain energy of the projectile are almost unchanged during the perforation; and (5) the steel liner is distributed on the rear surface of the concrete.

2.1. Conversion Formula of the Equivalent Thickness. According to Jing [31], when a homogeneous target and a steel plate having the same thickness are impacted by a projectile under the same incident angle, they can be considered equivalent if the ballistic limit velocity or the residual velocity caused by a uniform impact velocity is the same. In this section, the equivalent criterion for the same ballistic limit velocity is adopted. 
Many scholars have proposed a series of formulas for the ballistic limit velocity through steel plates or concrete. In terms of perforating steel plates, the Taylor formula [32], the Ballistics Research Laboratory (BRL) formula [14], and the Bethe formula [33] are included. In terms of perforating concrete, the Modified Ballistics Research Laboratory (MBRL) formula, the U.S. Army Corps of Engineers (ACE) formula, the National Defense Research Committee (NDRC) formula, and the Commissariat à l'Énergie Atomique et Électricité de France (CEA-EDF) formula $[34,35]$ are included. By making any ballistic limit velocity of a steel plate equal to that of concrete, the conversion formula for their thicknesses can be obtained. According to reference [12], the BRL\&CEA-EDF conversion formula has a high accuracy, and thus it was selected for this study, which is as follows:

$$
t_{\text {eq }}=\frac{2896 d^{1 / 16}}{f_{\mathrm{c}}^{0.375}}\left(\frac{m}{\rho_{\mathrm{c}}}\right)^{1 / 8} t_{\mathrm{s}}^{9 / 16}
$$

where $t_{\mathrm{eq}}, f_{\mathrm{c}}$, and $\rho_{\mathrm{c}}$ are the concrete equivalent thickness, compressive strength, and mass density, respectively. $M$ is the projectile mass, $d$ is the projectile diameter, and $t_{\mathrm{s}}$ is the steel liner thickness.

\subsection{Theoretical Formula for the Perforation Resistance.} Figure 1 shows the equivalent principle between a rear steel liner and a concrete matrix. According to equation (1) and Figure 1, the composite target can be converted into a plain concrete one, and the relationship between them is as follows:

$$
h_{\mathrm{eq}}=h+t_{\mathrm{eq}},
$$

where $h_{\mathrm{eq}}$ is the total thickness of the composite target obtained by converting the steel liner into concrete and $h$ is the original thickness of the concrete portion in the composite target.

When a projectile perforates a plain concrete target with a certain thickness vertically, it goes through three failure stages: front crater scabbing, tunnel damage, and rear crater spalling. According to three stages in Figure 2, the cone slope angle $\varphi$ yields the following formula:

$$
\varphi=\tan ^{-1}\left(\frac{D_{c, \mathrm{r}}-d}{2 h_{c, \mathrm{r}}}\right)
$$

where $D_{\mathrm{c}, \mathrm{r}}$ and $h_{\mathrm{c}, \mathrm{r}}$ are the rear crater equivalent diameter and depth, respectively.

According to reference [19], the projectile yields the following formula when perforating the target based on the principle of kinetic energy conservation:

$$
\frac{1}{2} m V_{0}^{2}=\frac{1}{2} m V_{\mathrm{bl}}^{2}+\frac{1}{2} m V_{\mathrm{r}}^{2}+\frac{1}{2} \rho_{c} \Omega V_{\mathrm{rf}}^{2},
$$

where $V_{0}, V_{\mathrm{bl}}$, and $V_{\mathrm{r}}$ are the projectile impact velocity, ballistic limit velocity, and residual velocity, respectively. $\Omega$ and $V_{\text {rf }}$ are the ejecting concrete volume and velocity of the rear crater, correspondingly.

According to references $[19,20]$ and by considering equation (2), the following empirical formulas can be obtained:

$$
\begin{aligned}
h_{\mathrm{c}, \mathrm{r}} & = \begin{cases}0.5 h_{\mathrm{eq}}, & \frac{h_{\mathrm{eq}}}{d} \leq 5, \\
2.5 d, & \frac{h_{\mathrm{eq}}}{d}>5,\end{cases} \\
\Omega & =\frac{\pi}{12} h_{\mathrm{c}, \mathrm{r}}\left(4 \tan ^{2} \varphi h_{\mathrm{c}, \mathrm{r}}^{2}+6 d \tan \varphi h_{\mathrm{c}, \mathrm{r}}+3 d^{2}\right), \\
V_{\mathrm{rf}} & =\eta V_{\mathrm{r}},
\end{aligned}
$$

where $\eta$ is the velocity reduction coefficient of the ejecting concrete.

Given the target perforation limit model proposed in reference [19], the following empirical formulas can also be obtained when taking equation (2) into account:

$$
\begin{aligned}
S & =82.6 f_{\mathrm{c}}^{-0.544}, \quad f_{\mathrm{c}}(\mathrm{MPa}), \\
I_{\mathrm{bl}} & = \begin{cases}\left(\frac{h_{\mathrm{eq}}}{2 d}+\frac{h_{\mathrm{n}}}{2 d} \cdot \frac{h_{\mathrm{eq}}}{5 d}\right)^{2} \cdot \frac{\pi d}{4 h_{\mathrm{n}}}, & \frac{h_{\mathrm{eq}}}{d}<\frac{10 h_{\mathrm{n}}}{5 d+h_{\mathrm{n}}}, \\
\left.\frac{\pi}{2 d}-\frac{h_{\mathrm{eq}}}{2 d}+\frac{h_{\mathrm{n}}}{2 d} \cdot \frac{h_{\mathrm{eq}}}{5 d}\right), & \frac{10 h_{\mathrm{n}}}{5 d+h_{\mathrm{n}}} \leq \frac{h_{\mathrm{eq}}}{d} \leq 5, \\
\frac{\pi}{2}\left(\frac{h_{\mathrm{eq}}}{d}-2.5\right), & \frac{h_{\mathrm{eq}}}{d}>5,\end{cases} \\
V_{\mathrm{bl}}^{2} & =\frac{S f_{\mathrm{c}} d^{3} I_{\mathrm{bl}}}{m},
\end{aligned}
$$

where $S$ is a dimensionless empirical parameter. $I_{\mathrm{bl}}$ is a dimensionless prediction parameter of the ballistic limit. $h_{\mathrm{n}}$ is the length of the projectile nose.

As regards to equation (9), calculating the ballistic limit characteristic of steel liner concrete instead of plain concrete is improved, which includes three conditions. As shown in Figure 3, the schematics of three perforation scenarios are illustrated corresponding to three conditions of equation (9), respectively.

Equations (4)-(10) are combined, and the formula of projectile residual velocity is obtained as follows:

$$
V_{\mathrm{r}}=\sqrt{\frac{m V_{0}^{2}-S f_{\mathrm{c}} d^{3} I_{\mathrm{bl}}}{m+(\pi / 12) \rho_{\mathrm{c}} h_{\mathrm{c}, \mathrm{r}} \eta^{2}\left(4 \tan ^{2} \varphi h_{\mathrm{c}, \mathrm{r}}^{2}+6 d \tan \varphi h_{\mathrm{c}, \mathrm{r}}+3 d^{2}\right)}}
$$

On this basis, the standard for evaluating the perforation resistance of composite targets can be deduced as follows:

$$
\frac{E_{\mathrm{r}}}{E_{0}}=\frac{m V_{0}^{2}-S f_{\mathrm{c}} d^{3} I_{\mathrm{bl}}}{V_{0}^{2}\left[m+(\pi / 12) \rho_{\mathrm{c}} h_{\mathrm{c}, \mathrm{r}} \eta^{2}\left(4 \tan ^{2} \varphi h_{\mathrm{c}, \mathrm{r}}^{2}+6 d \tan \varphi h_{\mathrm{c}, \mathrm{r}}+3 d^{2}\right)\right]} .
$$

2.3. Verification and Analysis of the Theoretical Formula. If the impact velocity is known and unchanged, $E_{\mathrm{r}} / E_{0}$ critically depends on the projectile residual velocity. On the 


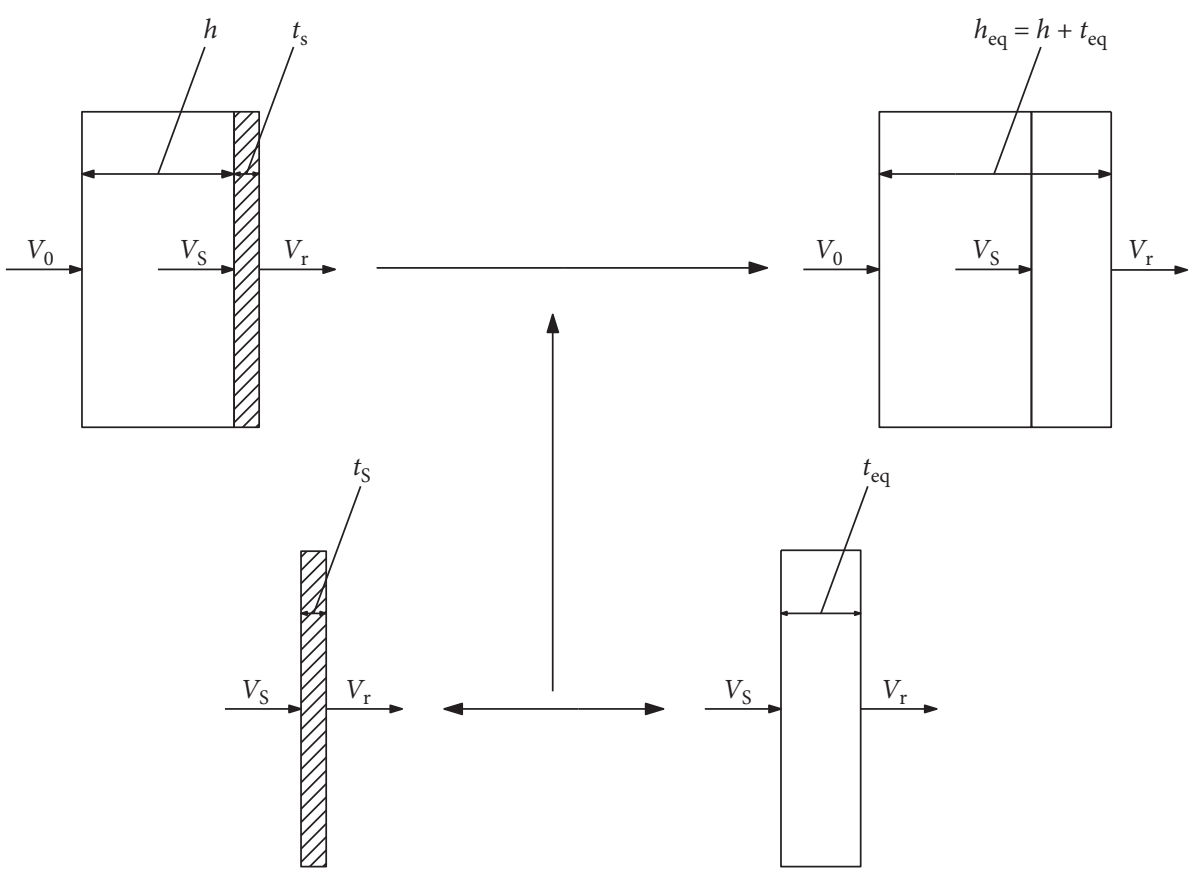

FIGURE 1: Equivalence principle between a rear steel liner and a concrete matrix.

contrary, the projectile residual velocity can be directly measured by tests. Therefore, our discussion focuses on the projectile residual velocity and its use for evaluating the perforation resistance of composite targets.

Equation (11) was utilized to calculate the perforation experiments in reference [30]. The mass, diameter, length, nose length, and caliber-radius-head $(\mathrm{CRH})$ of the test projectile were $0.42 \mathrm{~kg}, 25.3 \mathrm{~mm}, 152 \mathrm{~mm}, 42 \mathrm{~mm}$, and 3 , respectively. $675 \mathrm{~mm} \times 675 \mathrm{~mm}$ targets with different thicknesses $(100 \mathrm{~mm}, 150 \mathrm{~mm}, 200 \mathrm{~mm}$, and $300 \mathrm{~mm})$ were considered. The concrete compressive strength, applied with a $1 \mathrm{~mm}$ rear steel liner, was $41 \mathrm{MPa}$. In the calculations, the residual velocity of the projectile perforating the previous target can be regarded as the impact velocity of the subsequent one. The various experimental layouts and research objects are shown in Figure 4. The notation " $100+100+100(1) "$ in Figure 4(a) indicates the combination of three targets having all a thickness of $100 \mathrm{~mm}$ to obtain a segmented target, where the third one is attached with a $1 \mathrm{~mm}$ rear steel liner; the other notations have similar meaning.

According to the research of Avraham [36] and Li et al. [37], $\varphi$ of a rear crater was set to $66^{\circ} . \eta$ from equation (11) is affected by many factors, such as the projectile impact velocity, the volume of spalling concrete in the rear crater, and the thickness of the steel liner attached to the rear target surface. The value of $\eta$ in the residual velocity formula for a composite target is discussed, considering the effect of a rear steel liner. Figure 5 compares the calculated and experimental values of the projectile residual velocity for different concrete thicknesses, and it can be seen that the predicted residual velocity was decreased when $\eta$ was increased from 0.05 to 0.3 for a research target with a certain thickness $(100 \mathrm{~mm}, 150 \mathrm{~mm}, 200 \mathrm{~mm}$, and $300 \mathrm{~mm})$. This was mainly

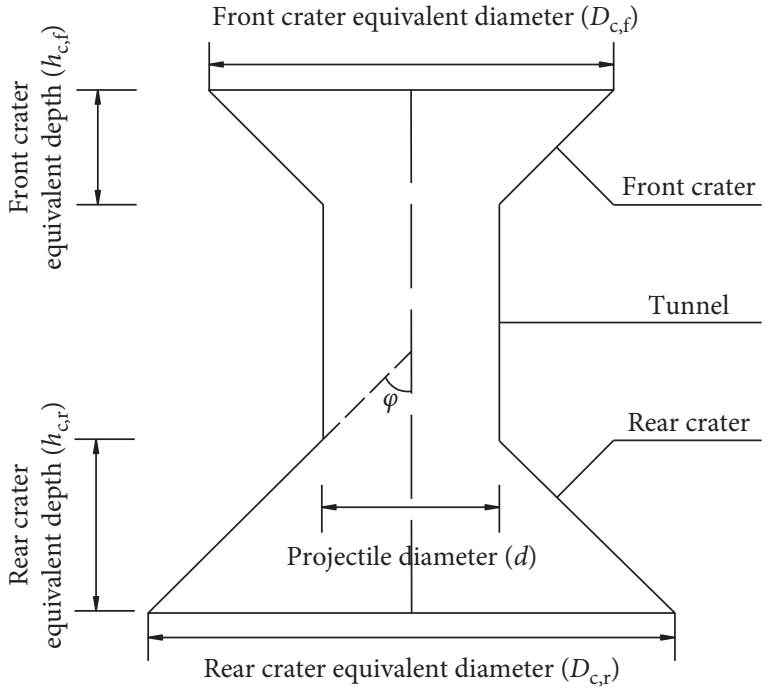

FIgURE 2: Three stages of the perforation damage in concrete targets.

because the kinetic energy of a whole system was conserved and the consumption of the projectile kinetic energy in the target was becoming more with an increase in $\eta$, which meant its residual kinetic energy was decreased gradually, and thus the projectile residual velocity was decreased correspondingly under the same strike velocity. On the contrary, except for a few experimental values from Figure 5(a) in the four working conditions, the predicted values of the projectile residual velocity were in a good agreement with the measured ones when $\eta=0.15$. The little inconsistency between the predicted and experimental values might be due to a certain amount of steel bars in the research target, which provided a perforation resistance 


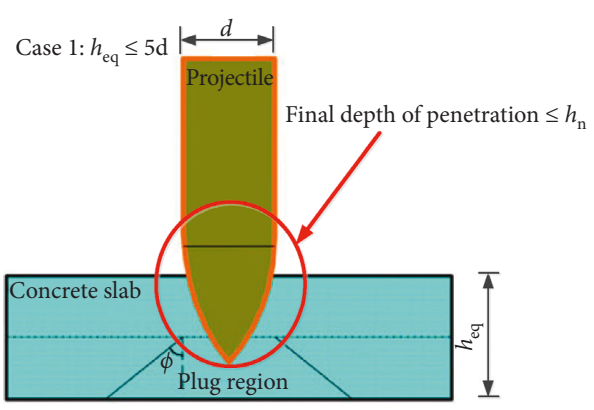

(a)

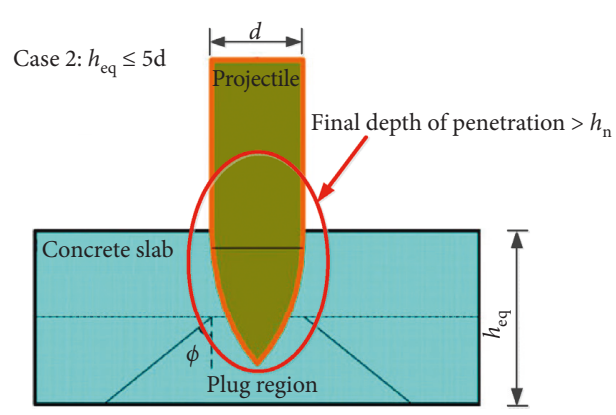

(b)

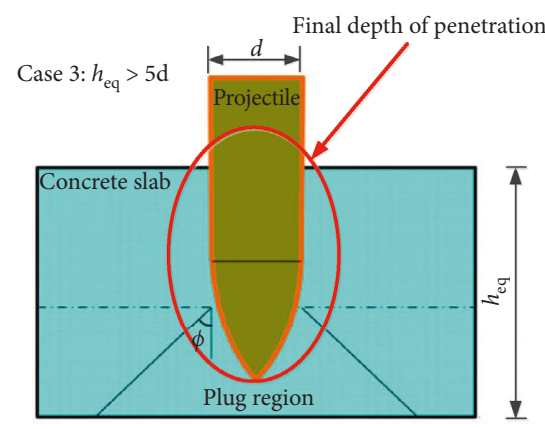

(c)

FIGURE 3: Schematics of perforation scenarios corresponding to the improved equation (9).

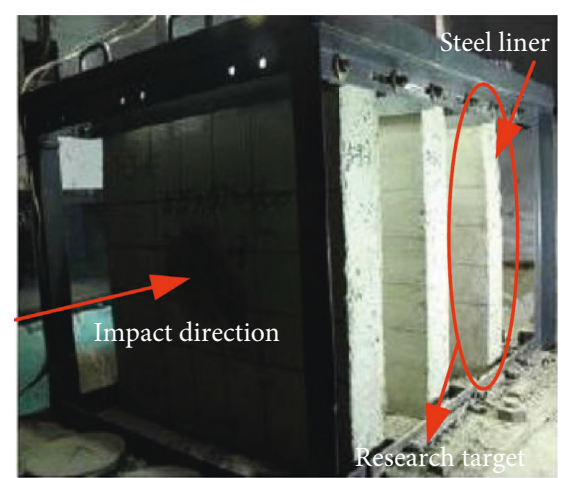

(a)

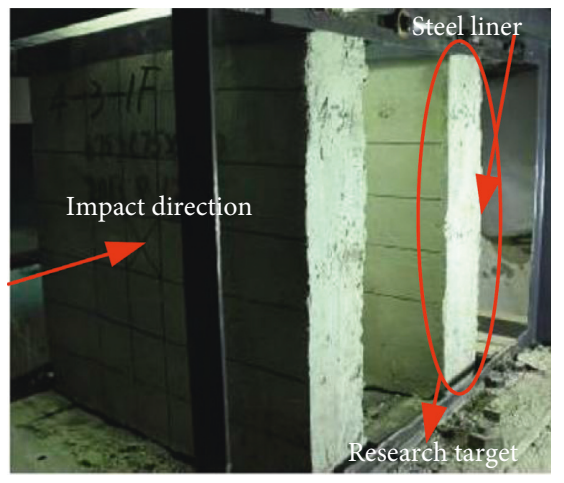

(c)

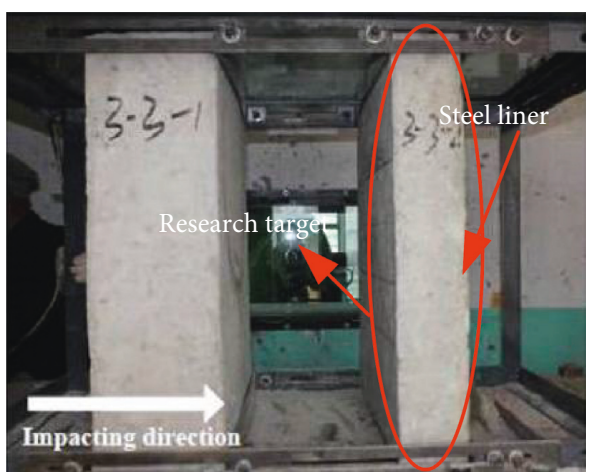

(b)

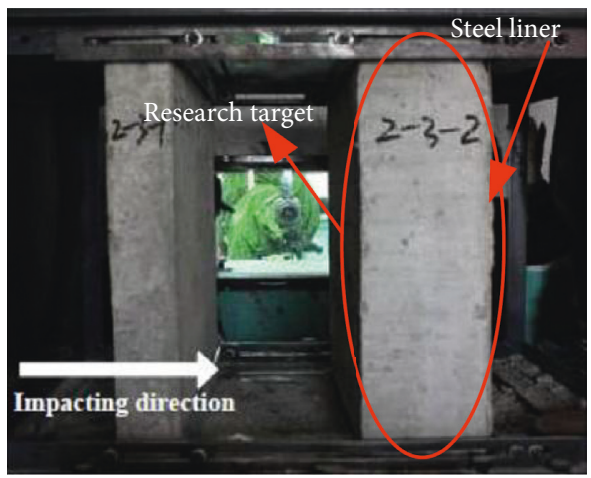

(d)

Figure 4: Continued. 


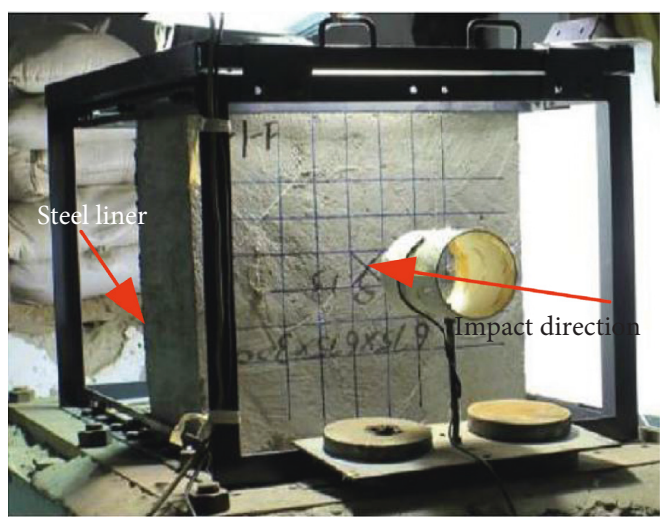

(e)

FiguRE 4: Experimental layout and the research object of each target [30]. (a) $100+100+100$ (1). (b) $200+100(1)$. (c) $150+150(1)$. (d) $100+200(1)$. (e) 300(1).
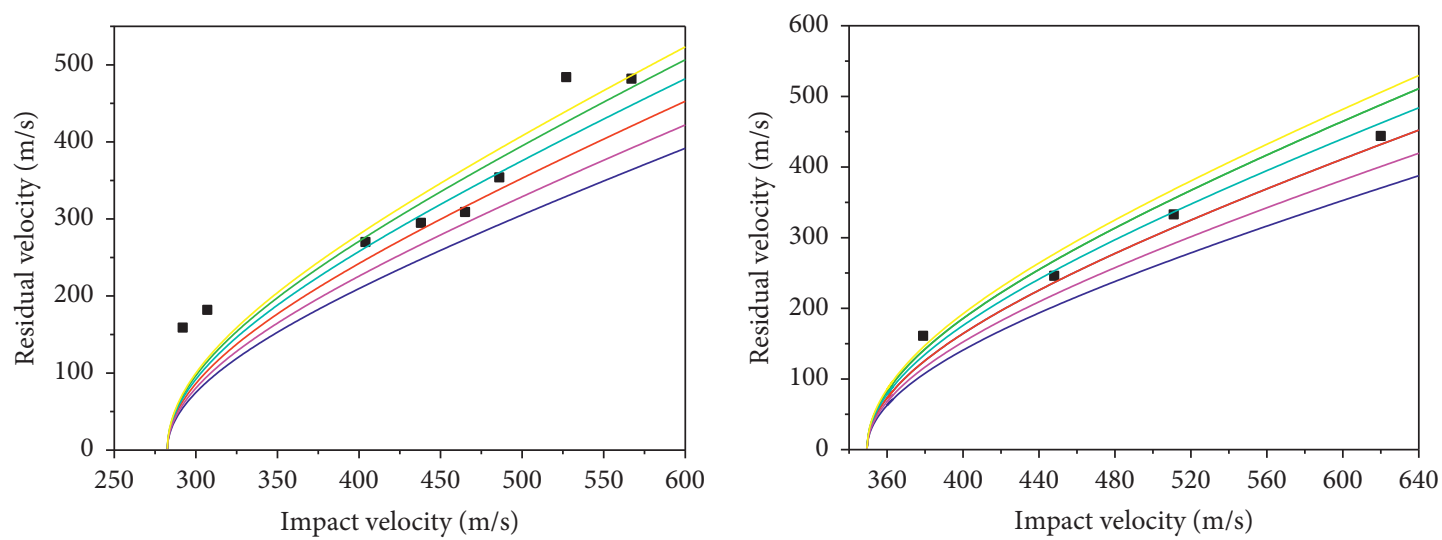

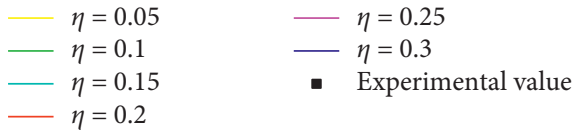

(a)
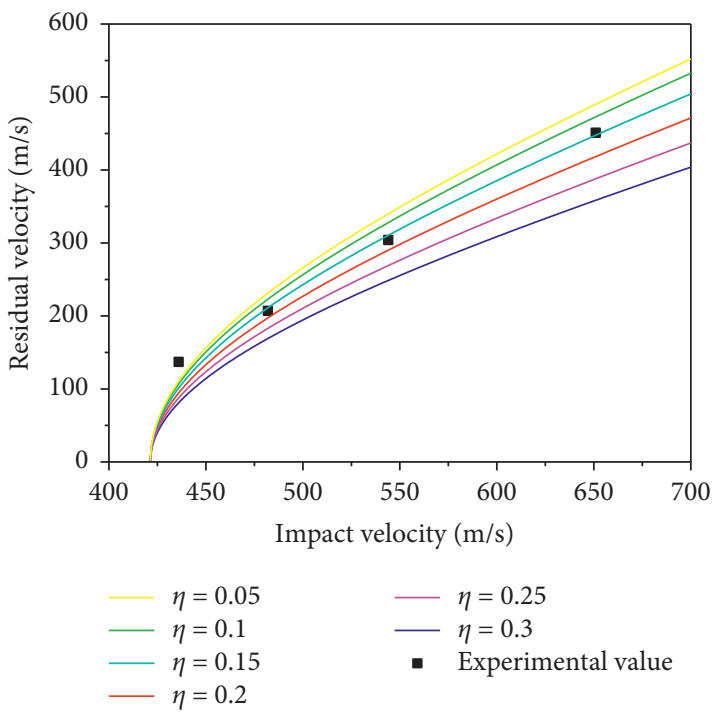

(c)

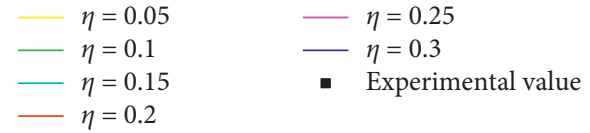

(b)

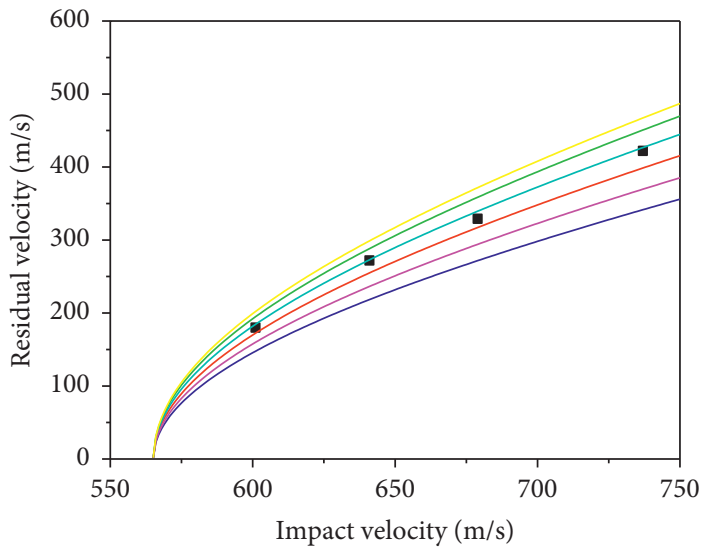

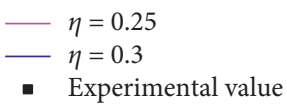

(d)

FIGURE 5: Comparison between calculated and experimental values of the projectile residual velocity for different concrete thicknesses. (a) $100 \mathrm{~mm}$. (b) $150 \mathrm{~mm}$. (c) $200 \mathrm{~mm}$. (d) $300 \mathrm{~mm}$. 
force for the projectile, but the influence of steel bars was not considered in equation (11). However, on the whole, when $\eta=0.15$, the formula for the projectile residual velocity in composite targets is reasonable, which is considering the effect of a rear steel liner. Figure 6 compares the predicted model proposed in this paper $(\eta=0.15)$ and that by $\mathrm{Wu}$ et al. [30] for different concrete thicknesses, showing that the prediction accuracy of equation (11) is higher than that of the Wu et al.'s [30] model. Therefore, $E_{\mathrm{r}} /$ $E_{0}$ derived from this formula can be used to evaluate the perforation resistance of composite concrete targets with a rear steel liner.

\section{Numerical Simulations}

3.1. Establishment of FEM Model. The geometric models of a projectile and target were based on penetration tests of steel liner concrete targets carried out in reference [29]. As regards to the FEM model of this paper, a concrete target with a $3 \mathrm{~mm}$ front steel liner was taken as an example because there were many types of composite targets in reference [29]. The Lagrange algorithm was adopted for the whole model in ANSYS/LS-DYNA. Considering symmetry and computational efficiency, a quarter model (1:1 setting model) was established. The projectile, concrete, and steel liner were used by solid164 element, and the steel liner and concrete were managed by common joints. The symmetrical boundary constraints were set on the symmetrical surface, while the displacement boundary constraint was applied around the target. ESTS is one of contact types, which can make a connection between the projectile, concrete, and steel liner by CONTACT_ERODING_SURFACE_TO_SURFACE (ESTS). Both the geometry and FEM model of the projectile and target are shown in Figure 7. A plastic kinematic material model was used for the projectile and the steel liner, while a HJC cumulative damage model was adopted for concrete, which could meet the numerical calculation requirements. The constitutive relations of the two materials were as follows:

$$
\sigma_{\mathrm{y}}=\left[1+\left(\frac{\dot{\varepsilon}}{C}\right)^{1 / P}\right]\left(\sigma_{0}+\beta E_{P} \varepsilon_{P}^{\text {eff }}\right),
$$

where $\sigma_{\mathrm{y}}, \sigma_{0}$, and $\dot{\varepsilon}$ are the actual yield stress, the initial yield stress, and the strain rate, respectively. Both $C$ and $P$ are the strain rate parameters. $\beta, \varepsilon_{P}^{\text {eff }}$, and $E_{P}$ are a hardening parameter, the effective plastic strain, and the plastic hardening modulus, respectively:

$$
\sigma^{*}=\left[A(1-D)+B\left(\frac{P}{f_{\mathrm{c}}^{\prime}}\right)^{N}\right]\left[1+C \ln \left(\frac{\dot{\varepsilon}}{\dot{\varepsilon}_{0}}\right)\right],
$$

where $\sigma^{*}$ is the equivalent stress. $A, B$, and $N$ are all limit surface parameters of the model. $D, C, P$, and $f_{c}^{\prime}$ are a damage parameter, a strain rate effect parameter, the actual hydrostatic stress, and the quasi-static uniaxial compressive strength, respectively. $\dot{\varepsilon}$ and $\dot{\varepsilon}_{0}$ are the strain rate and the datum strain rate, respectively.

The material parameters for the projectile, steel liner, and concrete were taken from references $[29,38]$. The specific parameters are summarized in Tables 1 and 2 .
Based on the model shown in Figure 7, an FEM model of a segmented concrete target with a $3 \mathrm{~mm}$ front steel liner is established in Figure 8, where the $100 \mathrm{~mm}$ concrete was divided into two $50 \mathrm{~mm}$ targets separated by a $50 \mathrm{~mm}$ interval and other settings were the same for the monolithic target.

3.2. Feasibility Verification of FEM Model. In this section, four typical working conditions in reference [29] were selected to verify the feasibility of this model by comparing damage conditions of the front and rear target surfaces. The results are displayed in Figure 9. The mark "3-0-334" in Figure 9 indicates that the projectile perforates vertically a composite target with a $3 \mathrm{~mm}$ front steel liner, which is at a speed of $334 \mathrm{~m} / \mathrm{s}$, and other working conditions are analogous. As shown in Figures 9(a) and 9(b), the front and rear surface of the target were subjected to compression and tension stress waves, respectively, during perforation, and thus the rear surface concrete peeled off and some radial cracks formed extending to the target edge. Because of the existence of a steel liner on the front surface, the concrete spalling and cracks were effectively restrained. The middle of a steel liner was impacted and extruded by a rigid projectile, which had a slight upward protuberance, but no cracks were formed. The damage characteristics shown in Figures 9(g) and 9(h) were similar to those in Figures 9(a) and 9(b). The only difference was the placement of the steel liner on the target rear surface, which resulted in the steel liner to have a downward protuberance and petal-shaped cracks affected by the tensile stress waves. As illustrated in Figures 9(c)-9(f), the composite targets were welded with steel liners on both sides, and their front and rear surfaces exhibited an upward and downward protuberance, respectively. Both of them produced no spalling or cracks. However, the steel liners in the simulation represented by Figures 9(f) and 9(h) were broken, although they had not been perforated in the actual tests. The possible reasons are as follows: (1) there was a greater randomness in tests, which was affected by the impact velocity, concrete, and steel liner strength as well as other factors, and thus it was a reasonable phenomenon that a few steel liners welded with the rear surface were not perforated and (2) the material model and parameters selected for this simulation still had some differences from the real situation, leading to the observed inconsistency in the damage characteristics. Tables 3 and 4 summarize the experimental and simulation results for the rear and front crater damages in "3-0-334" and "0-3-317," respectively. It was found that the simulated crater depth and diameter were in a good agreement with the experimental values, with errors less than $10 \%$. In summary, the above model adopted to conduct a penetration calculation of experiments in reference [29] is feasible to some extent because the numerical simulation is similar to experimental results.

\section{Numerical Analysis and Discussion}

4.1. Effect of Steel Liner Layout on the Perforation Resistance for a Monolithic Target. With regard to monolithic targets 


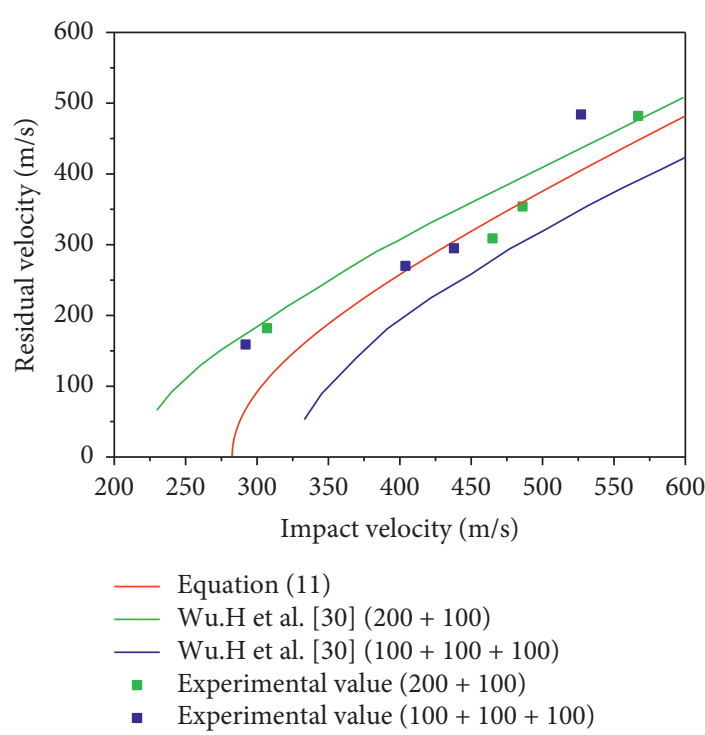

(a)

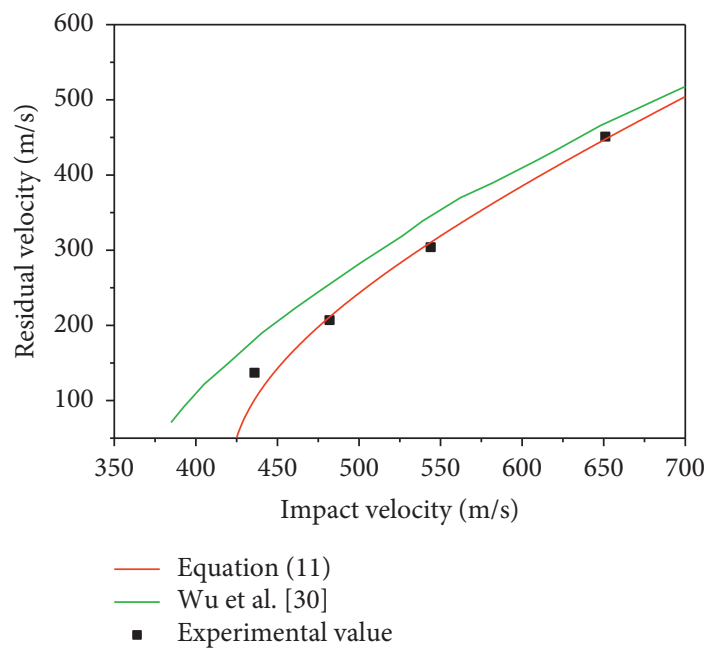

(c)

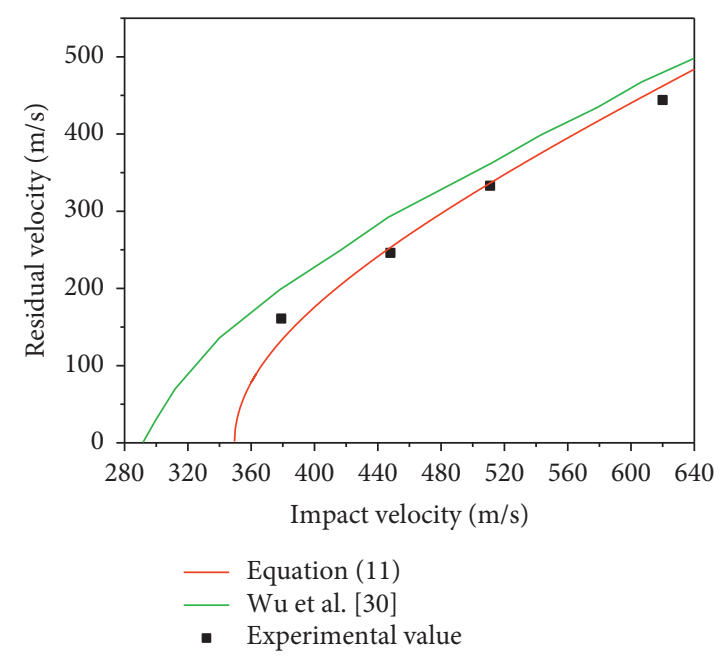

(b)

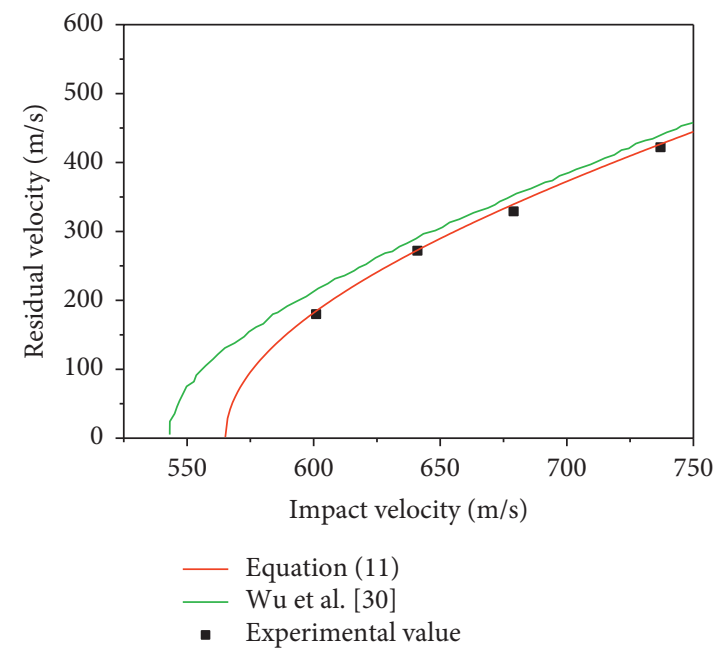

(d)

Figure 6: Comparison between the proposed prediction model and an existing one [30] for the projectile residual velocity under different concrete thicknesses. (a) $100 \mathrm{~mm}$. (b) $150 \mathrm{~mm}$. (c) $200 \mathrm{~mm}$. (d) $300 \mathrm{~mm}$.

consisting of steel liners with the same thickness, the antiperforation performance of them is quite different when the steel liner layout is changed. Therefore, the steel liner layout is one of the important references for optimal design of protective structures. In this section, a rigid projectile was assumed to vertically perforate composite targets at $317 \mathrm{~m} / \mathrm{s}$, and five working conditions were simulated: "3-0," "2-1," "1.5-1.5," "1-2," and " $0-3$ " (the two numbers in each notation indicate the thicknesses of the front and rear steel liners, respectively, in $\mathrm{mm}$ ).

Figure 10 plots the velocity-time history of projectiles with different steel liner layouts. As the thickness of steel liners was moved from the front to the back target surface, the residual velocity of projectiles was decreased gradually, indicating a corresponding increase in the perforation resistance of composite targets. Except for 3-0, when the steel liner was penetrated by projectiles during $400-$
$600 \mu \mathrm{s}$, the velocity of projectiles was decreased slowly. Furthermore, the compressive stress wave generated at the contact point was reflected into the tensile stress wave by the steel liner, when projectiles impacted on the material boundary. With the interaction of two stress waves, the projectile velocity remained unchanged, that was why each target in Figure 10 appeared a stable platform before $400 \mu$ s. Figure 11 shows the deceleration-time history of projectiles with different steel liner layouts. There were roughly three disturbances: at $0-150,200-400$, and $500-800 \mu \mathrm{s}$. The $0-150 \mu \mathrm{s}$ one was in a front craterappearing stage, and thus the projectile penetration was resisted by the front steel liner and concrete. Unfortunately, the front steel liner was perforated by a rigid projectile during $200-400 \mu \mathrm{s}$, and only concrete provided a continuous penetration resistance. Therefore, the deceleration disturbance at $200-400 \mu$ s was weaker than that 


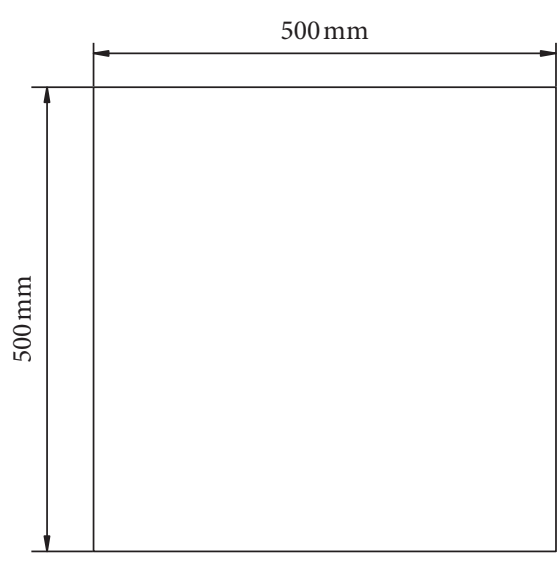

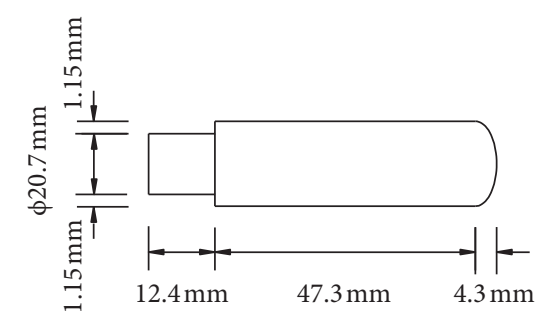

(a)

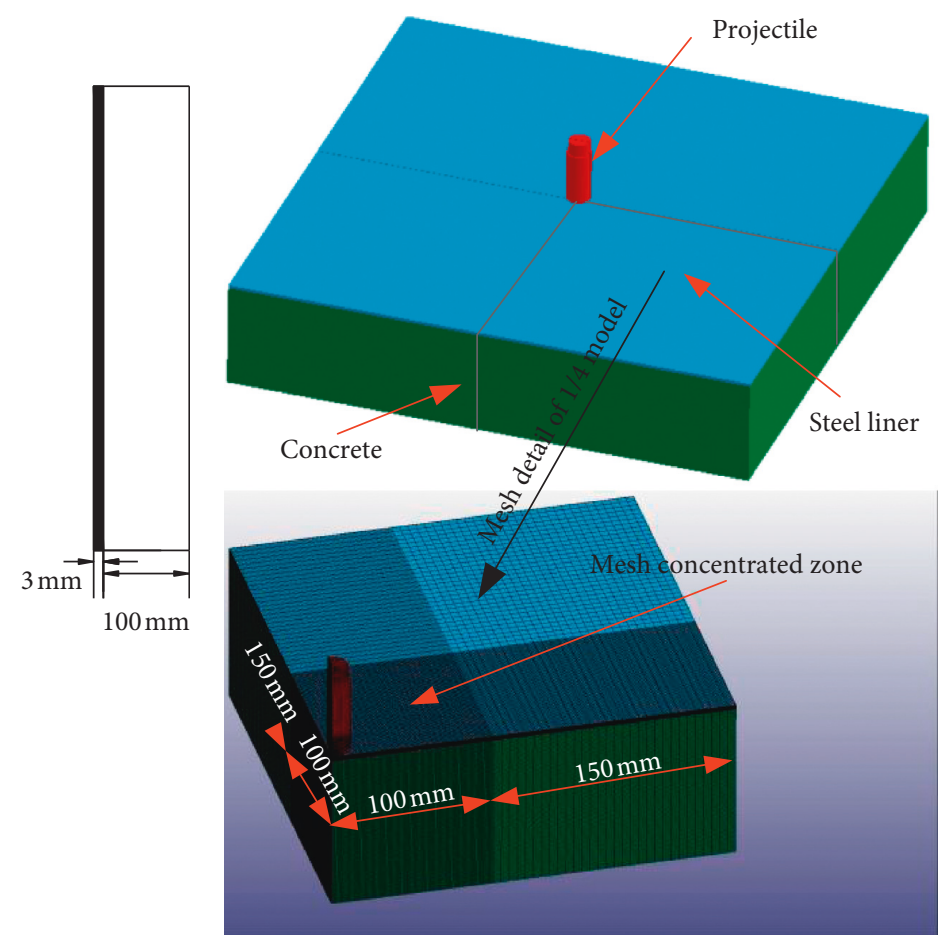

(b)

Figure 7: (a) Geometry size and (b) finite element model of projectile and target (3-0).

TABLE 1: Material model parameters of the projectile and steel liner.

\begin{tabular}{lccccccc}
\hline Name & Mass density $\left(\mathrm{g} / \mathrm{cm}^{3}\right)$ & Elastic modulus $(\mathrm{GPa})$ & Poisson's ratio & Yield stress $(\mathrm{MPa})$ & $\begin{array}{c}\text { Tangent modulus } \\
(\mathrm{MPa})\end{array}$ & $\begin{array}{c}\text { Hardening } \\
\text { parameter }\end{array}$ & $\begin{array}{c}\text { Failure } \\
\text { strain }\end{array}$ \\
\hline Projectile & 8.12 & 200 & 0.3 & 1726 & 1900 & 1 & 0.07 \\
Steel liner & 7.85 & 200 & 0.3 & 240 & 360 & 1 \\
\hline
\end{tabular}

TABle 2: Material model parameters of concrete.

\begin{tabular}{lcccccccccc}
\hline Mass density $\left(\mathrm{g} / \mathrm{cm}^{3}\right)$ & Shear modulus $(\mathrm{GPa})$ & $A$ & $B$ & $C$ & $N$ & $F_{\mathrm{C}}(\mathrm{MPa})$ & $T(\mathrm{GPa})$ & EPS0 & EFMIN \\
\hline 2.4 & 16.5 & 0.717 & 2.12 & 0.007 & 0.656 & 26 & 0.0025 & $1 \times 10^{-6}$ & 0.01 \\
\hline SFMAX & $P_{\mathrm{C}}$ & $U_{\mathrm{C}}$ & $P_{\mathrm{L}}(\mathrm{GPa})$ & $U_{\mathrm{L}}$ & $D_{1}$ & $D_{2}$ & $K_{1}$ & $K_{2}(\mathrm{GPa})$ & $K_{3}(\mathrm{GPa})$ \\
\hline 7 & 0.0117 & $6 \times 10^{-4}$ & 0.8 & 0.116 & 0.035 & 1 & & 85 & -171 & 208 \\
\hline
\end{tabular}

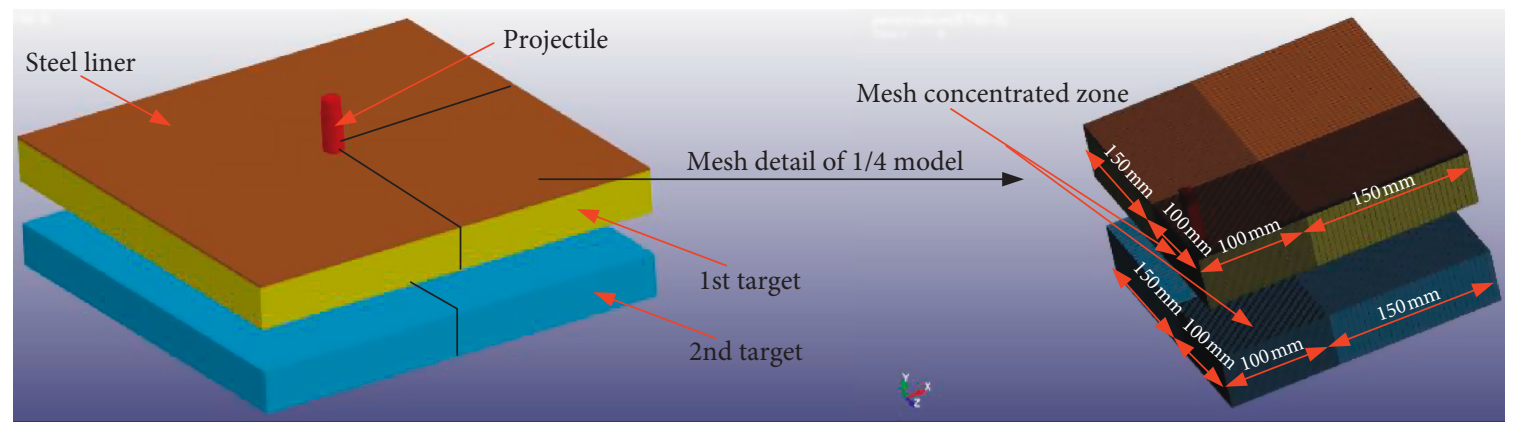

Figure 8: FEM model of projectile and segmented target (3-0-0-0). 

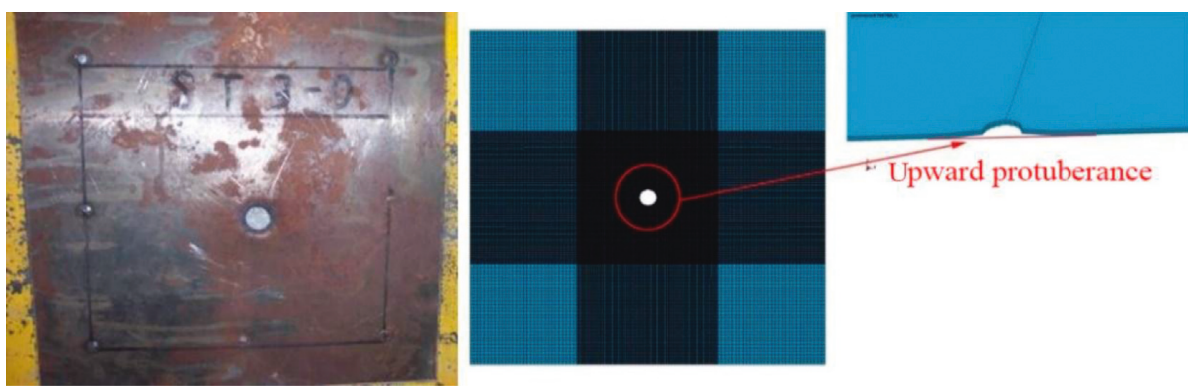

(a)
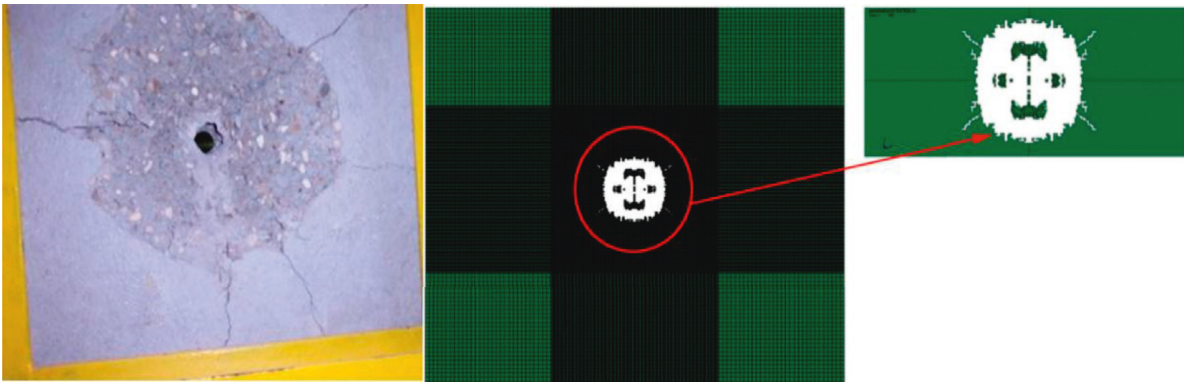

(b)

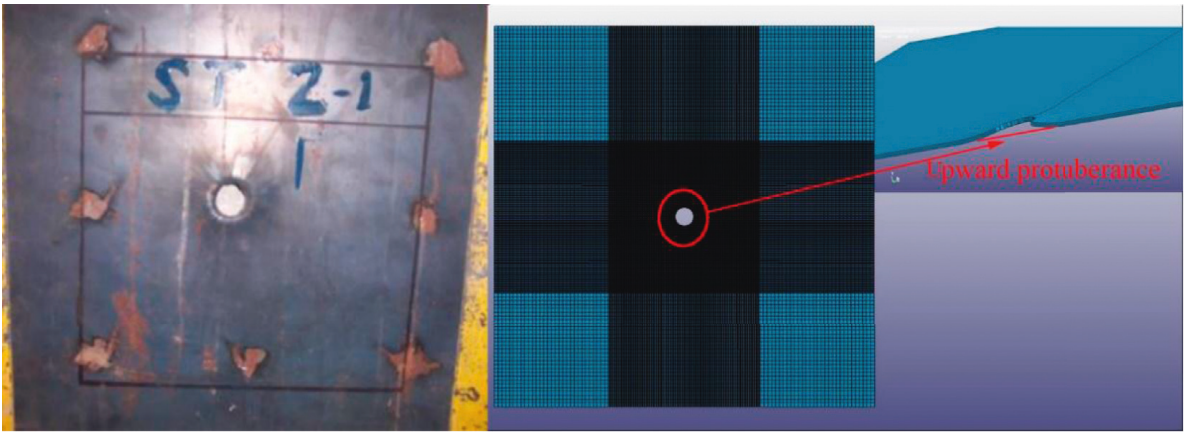

(c)
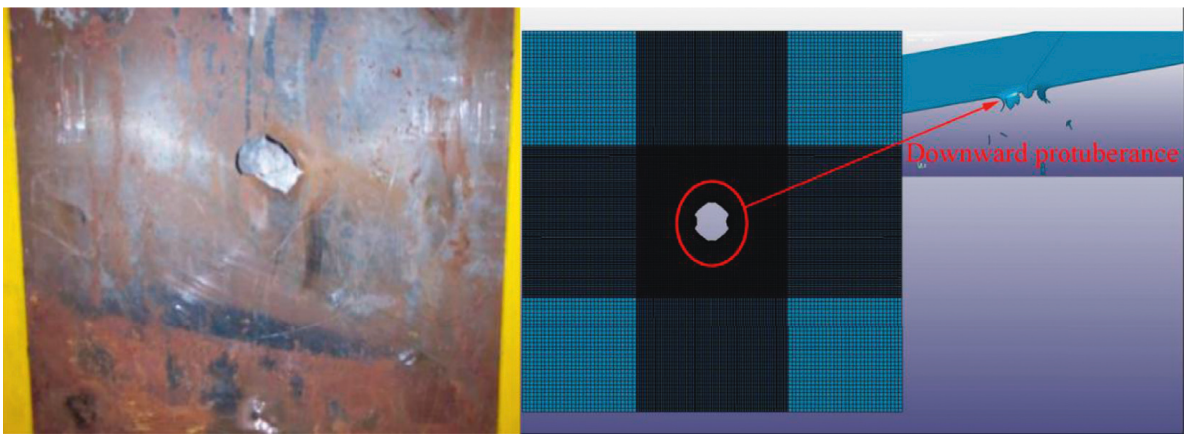

(d)

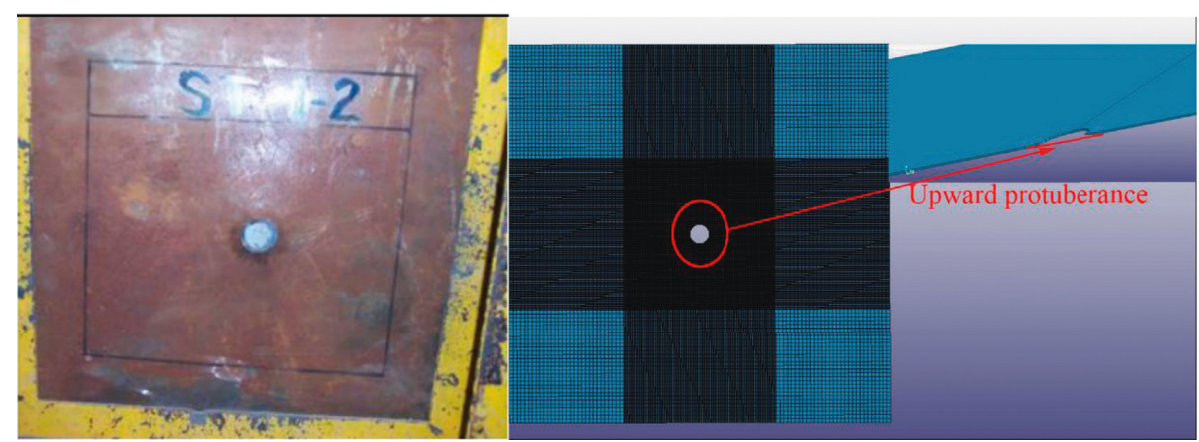

(e)

Figure 9: Continued. 


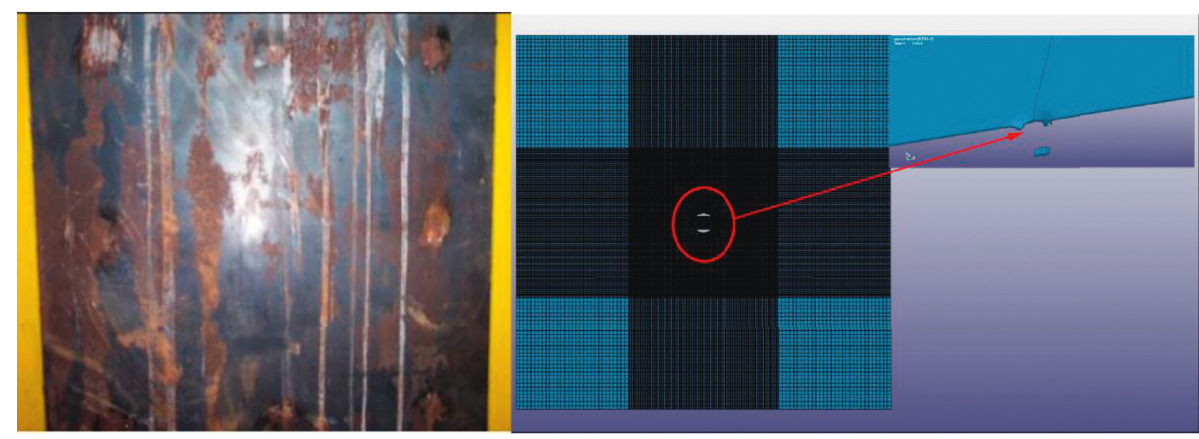

(f)

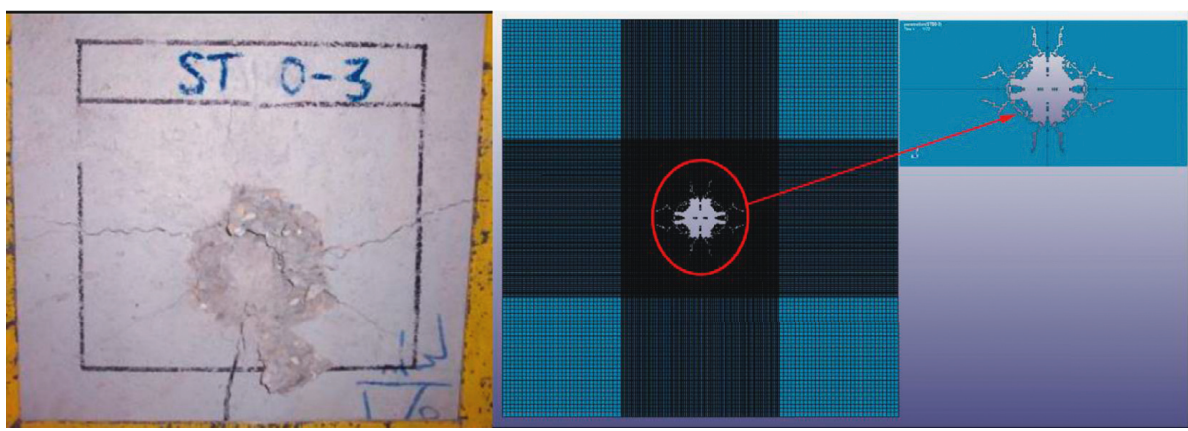

(g)
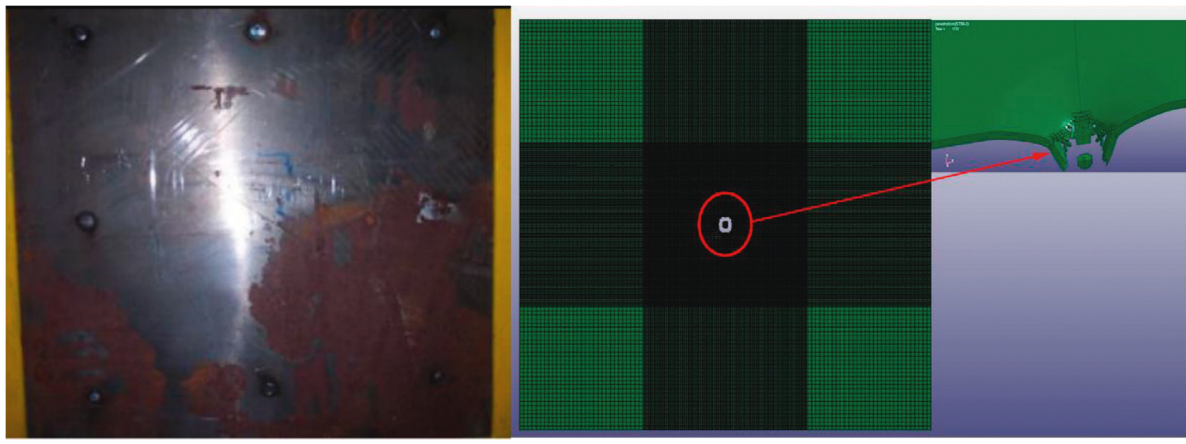

(h)

Figure 9: Comparison of experimental [29] and simulated results for the target damage (1/3): (a) front surface of target (3-0-334); (b) rear surface of target (3-0-334). Comparison of experimental [29] and simulated results for the target damage (3/3): (c) front surface of target (21-431); (d) rear surface of target (2-1-431); (e) front surface of target (1-2-331); (f) rear surface of target (1-2-331). Comparison of experimental [29] and simulated results for the target damage (2/3): (g) front surface of target (0-3-317); (h) rear surface of target (0-3-317).

TABLE 3: Comparison of experimental [29] and simulated results for the rear crater damage (3-0-334).

\begin{tabular}{lcccc}
\hline \multicolumn{2}{c}{$\begin{array}{c}\text { Rear crater depth }(\mathrm{mm}) \\
\text { Experiment }\end{array}$} & Error $(\%)$ & \multicolumn{2}{c}{ Rear crater mean diameter (mm) } \\
Simulation & & 5 & Experiment & Simulation \\
\hline 70 & 66.5 & 2.86 & 255 & 250.5 \\
70 & 68 & 1.43 & 258 & 255.5 \\
70 & 69 & 252 & 250.5 & 0.97 \\
\hline
\end{tabular}

TABLE 4: Comparison of experimental [29] and simulated results for the front crater damage (0-3-317).

\begin{tabular}{|c|c|c|c|c|c|}
\hline \multicolumn{2}{|c|}{ Front crater depth $(\mathrm{mm})$} & \multirow{2}{*}{ Error (\%) } & \multicolumn{2}{|c|}{ Front crater mean diameter $(\mathrm{mm})$} & \multirow{2}{*}{ Error (\%) } \\
\hline Experiment & Simulation & & Experiment & Simulation & \\
\hline 40 & 37.5 & 6.25 & 100 & 95.5 & 4.5 \\
\hline 40 & 38.5 & 3.75 & 100 & 97.5 & 2.5 \\
\hline 50 & 49 & 2 & 140 & 138 & 1.43 \\
\hline
\end{tabular}


at $0-150 \mu \mathrm{s}$. For $500-800 \mu \mathrm{s}$, there was a difference from the interaction time between the projectile and steel liner under five working conditions, probably as a consequence of the various thicknesses of each rear steel liner, which was also why the disturbance duration was becoming longer. Moreover, the deceleration disturbance was the greatest for $0-3$ and was decreased in the following order: $1-2>1.5-1.5>2-1>3-0$. It was found that the thicker the rear steel liner was, the more obvious the antiperforation effect the composite target had, consistently with Figure 10.

If no work caused by an external force is done in a system, the total energy of this system is conserved. Figure 12 plots energy-time history curves of the projectile impacting 0-3 composite target. Similar results are given by the other four conditions mentioned above. The projectile kinetic energy was the largest before penetrating; however, it was consumed by cracks and the spalling of concrete as well as the deformation of a steel liner when penetrating. After penetrating, the projectile kinetic energy remained unchanged, and the hourglass energy accounted for only $3 \%$ of the total energy in this system. Thus, the kinetic energy analysis is reliable based on this system. According to the target antiperforation comparison in Table 5, the perforation resistance of a target with a $3 \mathrm{~mm}$ rear steel liner was improved by about $10 \%$ compared with the target attached a $3 \mathrm{~mm}$ front steel liner. Table 6 shows the antiperforation contribution ratio of each target part, which is defined as the ratio between the kinetic energy consumed by one part of the composite target and the total kinetic energy consumed by three parts. Concrete was found to be the main part of resisting a projectile perforation for five working conditions, whose contribution ratio was more than $90 \%$. As regard to $2-1$, although the thickness of the rear steel liner was only half that of the front one, both contribution ratios of them were similar. As regards to 1.5-1.5 and 1-2, the contribution ratio of the rear steel liner was about 2 and 3 times, respectively, that of the front one. Figure 13 displays the extracted damage nephograms of the front and rear steel liner during the projectile perforation, which include working conditions of 21, 1.5-1.5, and 1-2. From marks in Figures 13(a)-13(f), it can be seen that the damage stress for the rear steel liner was 1.67 and 2.20 times of that for the front one at the conditions of 1.5-1.5 and 1-2, respectively, but both of them were almost the same at the condition of 2-1. The greater the steel liner damage stress was, the more the kinetic energy would be consumed, consistently with Table 6 . The rear steel liner could better prevent the projectile perforation than the front one, and this antipenetration effect would be more obvious with the increase in thickness. This was mainly due to two reasons: (1) The spalling concrete from the rear crater was more than that from the front one during the projectile perforation, according to experimental results of the crater depth and diameter in reference [29]. More spalling concrete could be restrained by the rear steel liner, which also had a certain hindrance effect on the projectile. The more concrete is restrained, the stronger its effect should be. (2) An additional tension membrane effect was produced on the back of the concrete by a rear steel liner. Compared with an additional

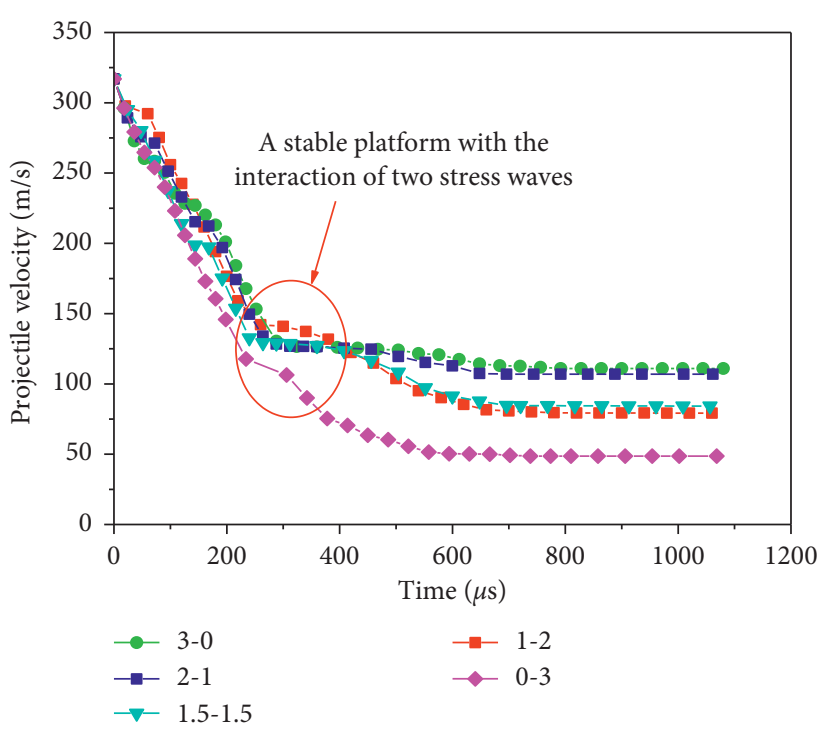

FIGURE 10: Velocity-time curves of a projectile with different steel liner layouts.

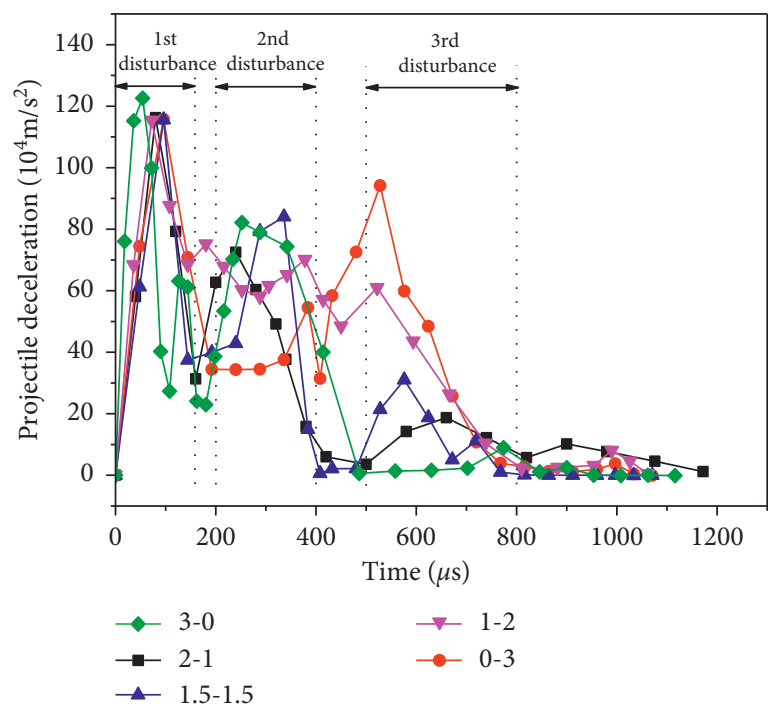

FIgURE 11: Deceleration-time curves of a projectile with different steel liner layouts.

compression membrane applied on the concrete front surface, it improved the concrete strength and provided a better perforation resistance.

Figure 14 displays the impact force-time curves of a projectile vertically perforating five different targets at $317 \mathrm{~m} / \mathrm{s}$. When the total thickness of steel liners was kept unchanged, the interaction between rear steel liners and projectiles was stronger, and thus their antipenetration effect was better than the front ones. It was worth noting that the impact force was determined by both impact velocity and contact stiffness. During the initial penetration stage, the impact force was mainly affected by the projectile velocity because of its larger value, which reached a maximum of $35 \mathrm{kN}$. During the later penetration stage, the projectile velocity was decreased sharply while the contact stiffness 


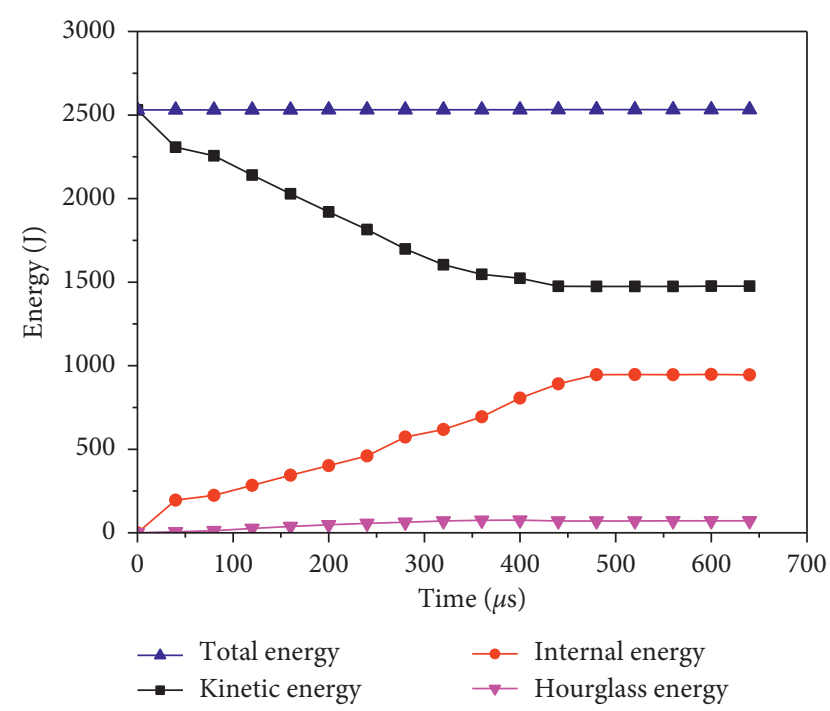

FIgURE 12: Time history curves of energy balance for impacting analysis (0-3).

TABLE 5: Comparison with antiperforation performance of targets with different steel liner layouts.

\begin{tabular}{lcc}
\hline Steel liner layout & Residual velocity $(\mathrm{m} / \mathrm{s})$ & $E_{\mathrm{r}} / E_{0}(\%)$ \\
\hline $3-0$ & 110.93 & 12.25 \\
$2-1$ & 106.94 & 11.38 \\
$1.5-1.5$ & 84.18 & 7.05 \\
$1-2$ & 79.23 & 6.25 \\
$0-3$ & 48.63 & 2.35 \\
\hline
\end{tabular}

TABLE 6: Contribution ratio of antiperforation performance with each part of targets.

\begin{tabular}{lccc}
\hline $\begin{array}{l}\text { Steel liner } \\
\text { layout }\end{array}$ & $\begin{array}{c}\text { Front steel liner } \\
(\%)\end{array}$ & $\begin{array}{c}\text { Concrete } \\
(\%)\end{array}$ & $\begin{array}{c}\text { Rear steel liner } \\
(\%)\end{array}$ \\
\hline $3-0$ & 6.92 & 93.08 & - \\
$2-1$ & 3 & 94.15 & 2.85 \\
$1.5-1.5$ & 1.69 & 95.28 & 3.03 \\
$1-2$ & 1.11 & 95.17 & 3.72 \\
$0-3$ & - & 94.16 & 5.84 \\
\hline
\end{tabular}

between projectiles and targets was enhanced by steel liners, leading to a "second sharp increase" of the projectile impact force; the peak values of this secondary impact force for 2-1, $1.5-1.5,1-2$, and $0-3$ were $29.03 \mathrm{kN}, 46.13 \mathrm{kN}, 52.50 \mathrm{kN}$, and $58.78 \mathrm{kN}$, respectively, which were close to or greater than $35 \mathrm{kN}$. Therefore, during middle- and low-speed perforations, the projectile impact force is more influenced by the contact stiffness between projectiles and targets than that by the impact velocity. Moreover, the peak values of such a secondary impact force are enlarged with the increase of the rear steel liner thickness. Based on this, the contact stiffness should be enhanced as much as possible in the protective structures with limited space, such as steel liners, ceramic/ fiber boards, and ceramic/aluminum alloy boards, which provide a better impact resistance.

Figure 15 plots the perforation process of composite targets with different steel liner layouts, which can be divided into three stages: initial, middle, and terminal penetration stages. During the initial stage, the steel liner is rapidly squeezed by the projectile, leading to an upward protuberance. Because of the impact compressive stress, the concrete is instantaneously crushed and destroyed, and a crater phenomenon appears subsequently. With the projectile continuous penetration, the squeezed target cannot make the overall impact stress uniform because the impact time is very short, which results in a continuous crushing failure and the formation of outwardly ejected debris. During the middle stage, a stable tunnel is developed in the target center because its overall impact stress tends to be uniform and the projectile deformation is very small simultaneously. During the terminal stage, the target crushing failure slows down with a decrease in the penetration velocity. The compressive stress wave generated by the impact stress reaches the target edge and is reflected as a tensile stress wave by the steel liner. Thus a rear crater is formed when the target is suffered by a tension damage. Then, the steel liner forms some petal-like cracks along the penetration direction and is perforated finally. Moreover, with the increase of the rear steel liner thickness, the formation of a "bulge" and a rear crater is "delayed," demonstrating that a rear steel liner improves its antiperforation performance.

\subsection{Effect of Steel Liner Layout on the Perforation Resistance} for a Segmented Target. Due to space limitation or special structural requirements for protective objects, segmented space targets are often used to resist terrorist attacks, and the steel liner layout also tends to be very important to their perforation resistance. In this case, the target was still assumed to be perforated vertically by the projectile at $317 \mathrm{~m} / \mathrm{s}$, and the penetration under five working conditions $(3-0-0-0$, $2-0-0-1,1.5-0-0-1.5,1-0-0-2$, and $0-0-0-3)$ was calculated. It should be noted that 2-0-0-1 represents a system with two targets, the first with a $2 \mathrm{~mm}$ front steel liner and the second with a $1 \mathrm{~mm}$ rear one, and other working conditions are also marked like this.

Figure 16 illustrates the velocity-time history of a projectile perforating segmented targets with different steel liner layouts. Similar to monolithic targets in Section 4.1, the projectile residual velocity was decreased gradually as the steel liner thickness was moved from the 1st target front face to the 2nd target rear surface, and thus the perforation resistance of the segmented target was enhanced correspondingly. Figure 17 plots the corresponding deceleration-time history of a projectile perforating segmented targets. The process and mechanism of each disturbance were similar to those of monolithic targets, which were still subject to three disturbances $(0-200$, $400-600$, and 600-800 $\mu \mathrm{s})$. However, the second and third disturbance occurred continuously without an obvious boundary line due to a shorter perforation time for each target. During the perforation, the peak deceleration of the projectile was obviously smaller than that in the monolithic targets, suggesting that the perforation resistance of segmented targets was inferior to that of monolithic targets under the same conditions. 


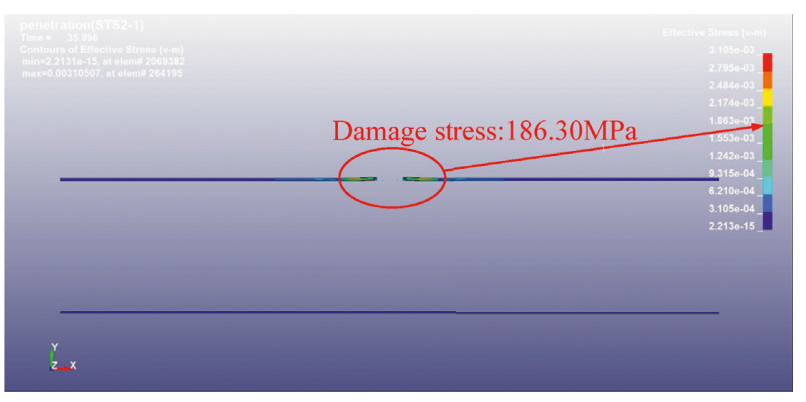

(a)

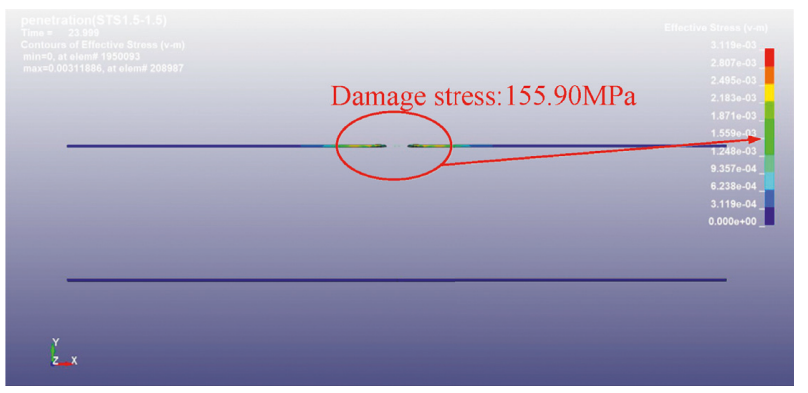

(c)

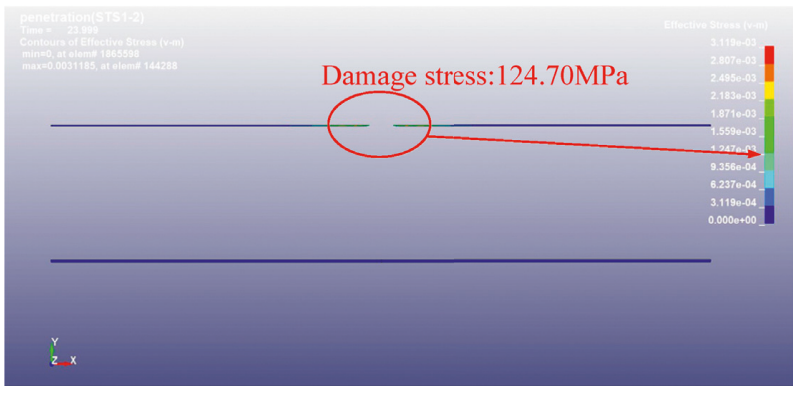

(e)

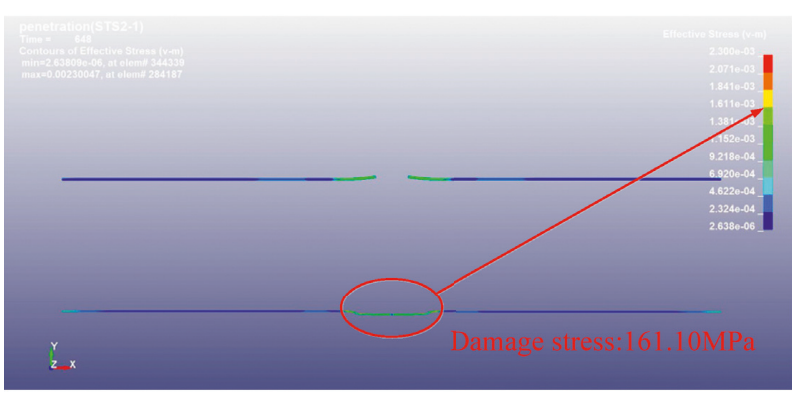

(b)

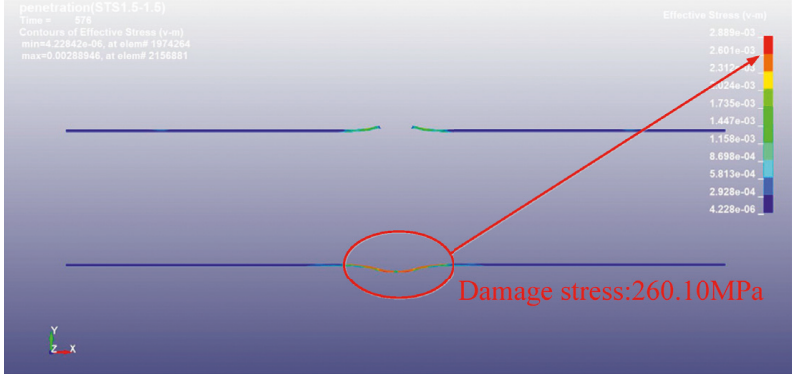

(d)

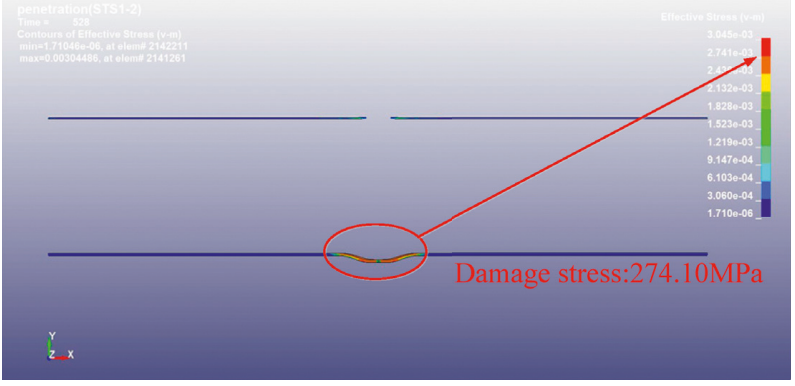

(f)

Figure 13: Damage nephograms of the front F and rear R steel liners under impact loading (1/2): (a) 2-1-F; (b) 2-1-R. Damage nephograms of the front $\mathrm{F}$ and rear $\mathrm{R}$ steel liners under impact loading (2/2): (c) 1.5-1.5-F; (d) 1.5-1.5-R; (e) 1-2-F; (f) 1-2-R.

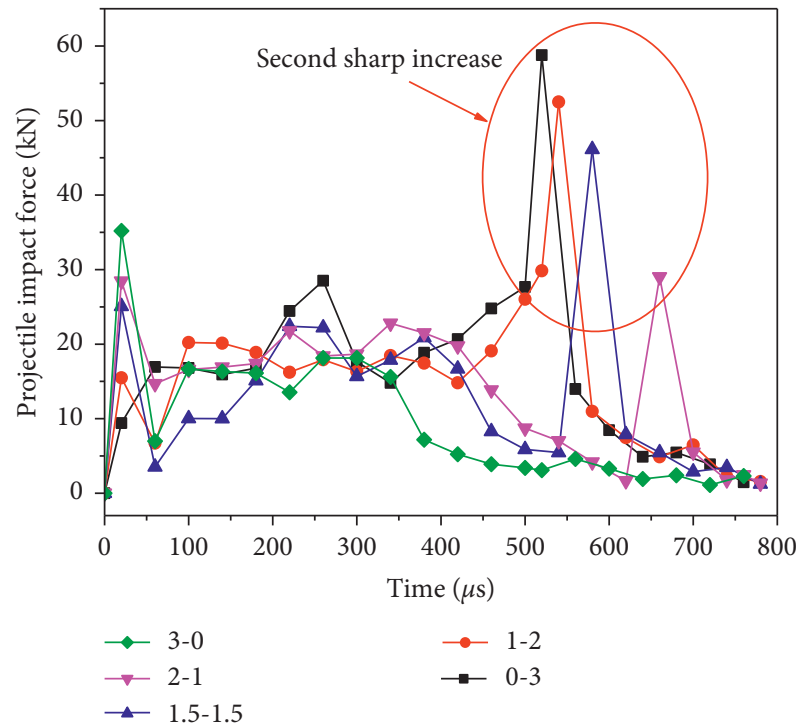

FIGURE 14: Impact force-time curves of a projectile with different steel liner layouts.
Figure 18 shows the extracted energy-time history curves of the projectile perforating 0-0-0-3 composite target, where the hourglass energy accounted for less than $1 \%$ of the total energy in this system, and the projectile kinetic energy could still be analyzed because other working conditions were similar to this. According to the antiperforation comparison of segmented targets in Table 7, the antiperforation performance of the target with a $3 \mathrm{~mm}$ rear steel liner attached to the second segment was about 13\% higher than that of the one with a $3 \mathrm{~mm}$ front steel liner attached to the first segment, which was not much different from $10 \%$. Therefore, the perforation resistance improvement provided by a $3 \mathrm{~mm}$ rear steel liner is independent on whether the target is segmented or not. However, for every corresponding working condition (e.g., 3-0 and 3-0-0-0), the perforation resistance of segmented targets was reduced by about $10 \%-16 \%$ compared with that of monolithic targets. This was probably due to the following reasons: (1) for a thinner target, the target impact stress was not fully homogenized and a stronger penetration resistance force could not be formed because of a shorter 


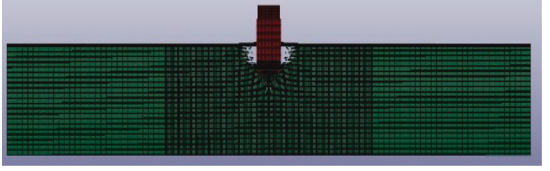

(a)

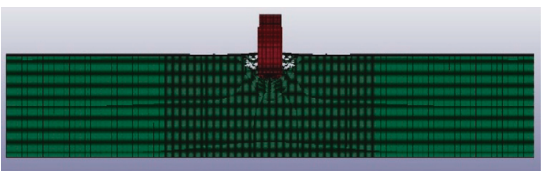

(d)

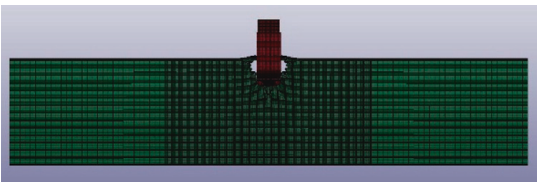

(g)

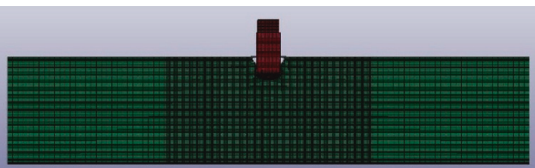

(j)

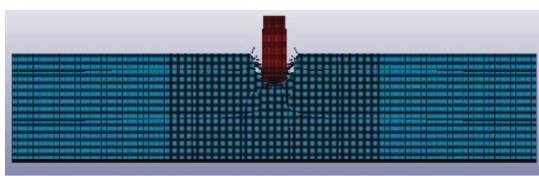

(m)

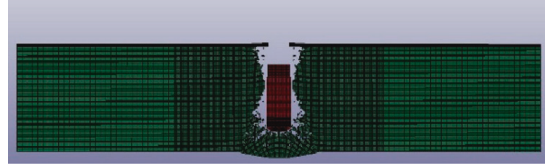

(b)

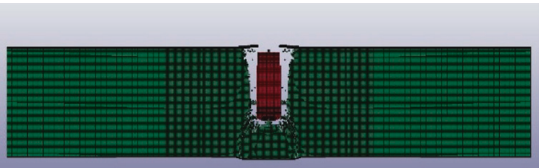

(e)

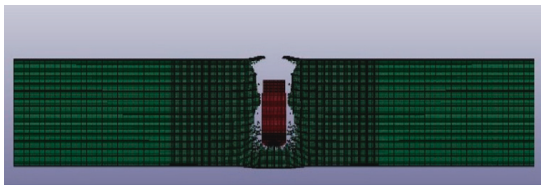

(h)

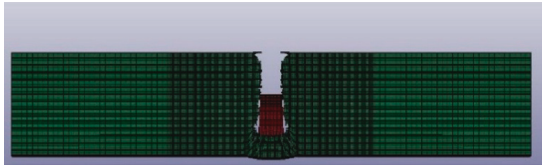

(k)

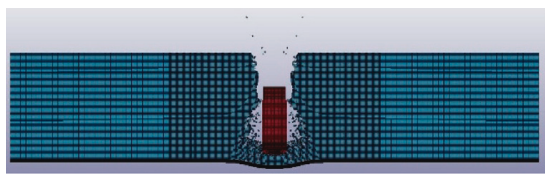

(n)

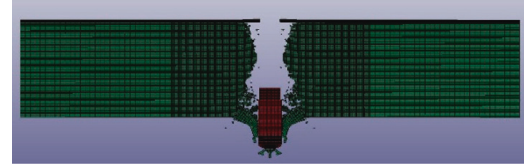

(c)

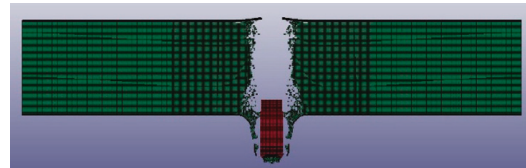

(f)

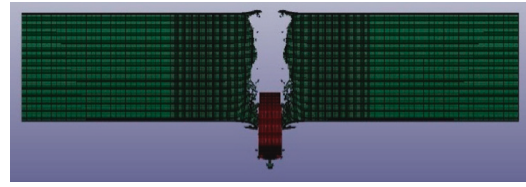

(i)

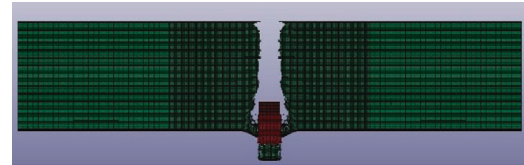

(1)

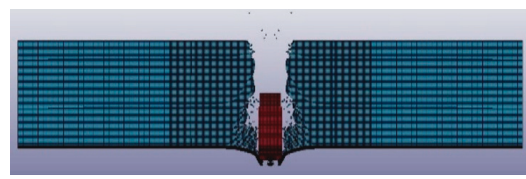

(o)

FIGURE 15: Perforation process of concrete targets with different steel liner layouts (1/2): (a) $108 \mu \mathrm{s}$ (3-0); (b) $450 \mu \mathrm{s}$ (3-0); (c) 900 $\mu$ s (3-0); (d) $90 \mu \mathrm{s}(2-1)$; (e) $540 \mu \mathrm{s} \mathrm{(2-1).} \mathrm{Perforation} \mathrm{process} \mathrm{of} \mathrm{concrete} \mathrm{targets} \mathrm{with} \mathrm{different} \mathrm{steel} \mathrm{liner} \mathrm{layouts} \mathrm{(2/2):} \mathrm{(f)} 912 \mu \mathrm{s}(2-1)$; (g) $96 \mu \mathrm{s}(1.5-1.5)$; (h) $456 \mu \mathrm{s}$ (1.5-1.5); (i) $900 \mu \mathrm{s} \mathrm{(1.5-1.5);} \mathrm{(j)} 96 \mu \mathrm{s} \mathrm{(1-2);} \mathrm{(k)} 480 \mu \mathrm{s} \mathrm{(1-2);} \mathrm{(1)} 912 \mu \mathrm{s} \mathrm{(1-2);} \mathrm{(m)} 100 \mu \mathrm{s}(0-3)$; (n) $720 \mu \mathrm{s}(0-3)$; (o) $972 \mu \mathrm{s}(0-3)$.

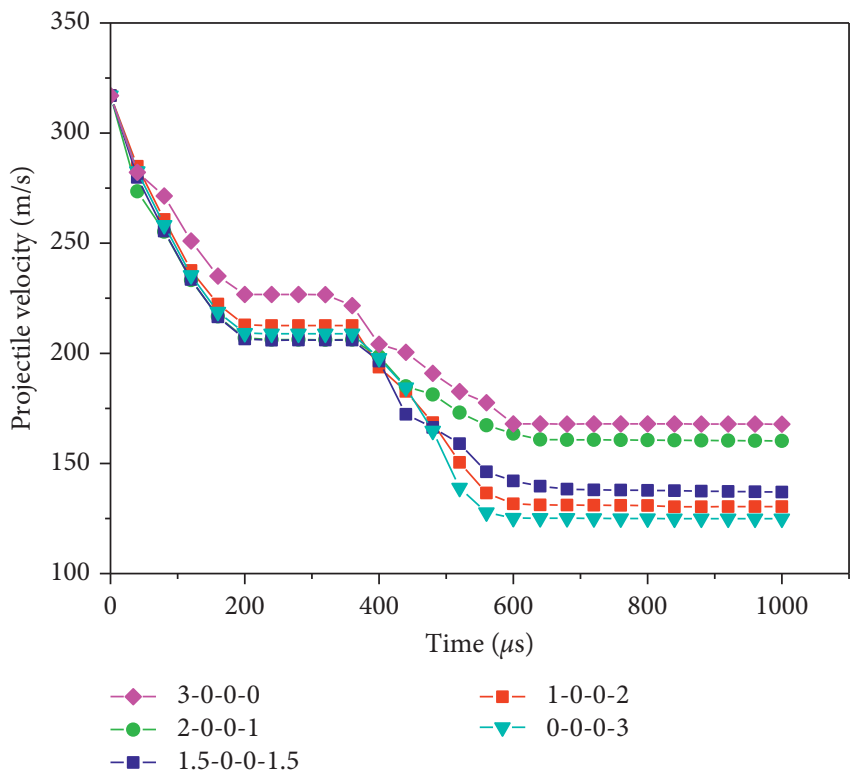

FIgURE 16: Velocity-time curves of projectile perforating segmented targets with different steel liner layouts.

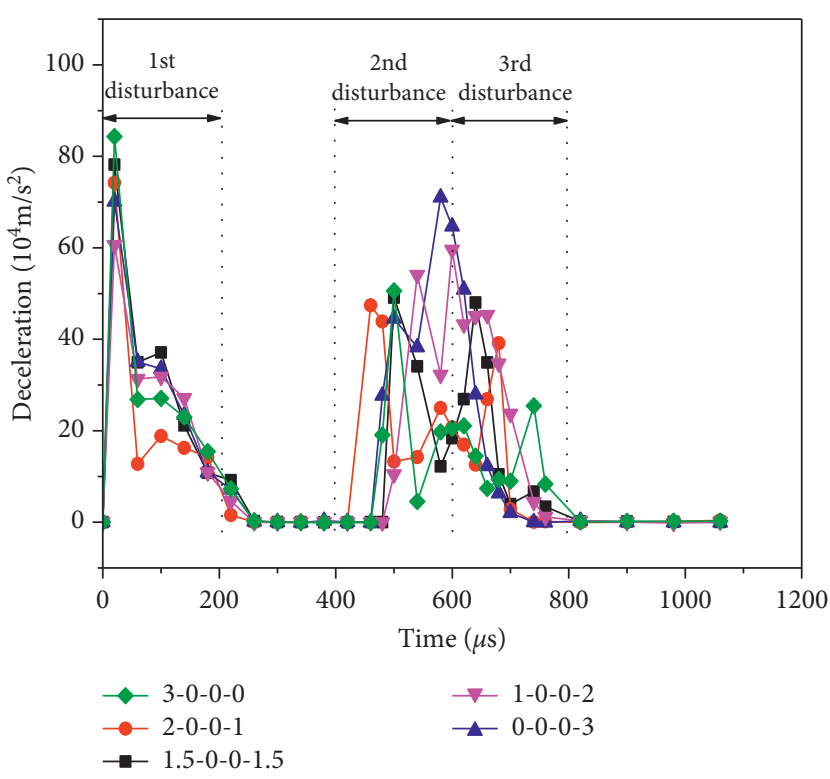

FIGURE 17: Deceleration-time curves of projectile perforating segmented targets with different steel liner layouts. 


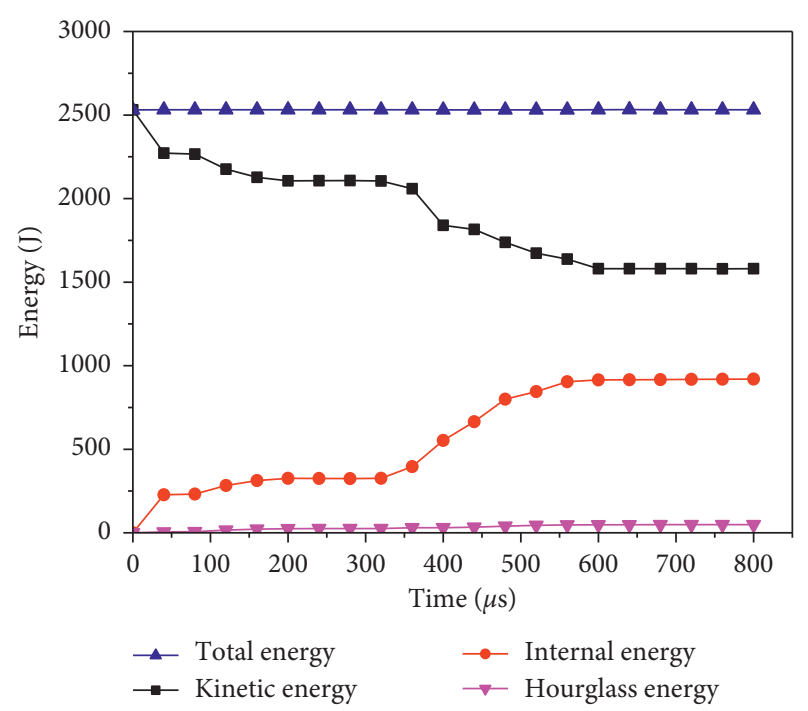

FIGURE 18: Time history curves of energy balance for impacting analysis $(0-0-0-3)$.

TABLE 7: Comparison with antiperforation performance of segmented targets with different steel liner layouts.

\begin{tabular}{lcc}
\hline Steel liner layout & Residual velocity $(\mathrm{m} / \mathrm{s})$ & $E_{\mathrm{r}} / E_{0}(\%)$ \\
\hline $3-0-0-0$ & 167.83 & 28.03 \\
$2-0-0-1$ & 160.26 & 25.56 \\
$1.5-0-0-1.5$ & 136.99 & 18.67 \\
$1-0-0-2$ & 130.37 & 16.91 \\
$0-0-0-3$ & 124.95 & 15.54 \\
\hline
\end{tabular}

impact time; and (2) there was a gap between the two targets that led to a discontinuous concrete obstruction effect. Therefore, the projectile damage and deformation were recovered to some extent after perforating the first target, facilitating the penetration of the second one. Table 8 lists the perforation resistance contribution ratio of each part for segmented targets. Except for a similar steel liner energy consumption with respect to the monolithic targets with different layouts, the projectile kinetic energy consumed in the second target was notably about $10 \%-20 \%$ more than that in the first one, and the corresponding perforation resistance was also better. It can be inferred that the segment with a great strength or thickness is arranged back as far as possible in the segmented target, which can reduce the damage effect of weapons. This analysis also provides some optimal design measures for segmented protective structures: (1) the minimum thickness of shock stress homogenization should be ensured in protective structures; (2) the interval of each protective object should be minimized to reduce the damage and deformation recovery of the projectile; (3) a protective object with a great strength and thickness should be placed at the end; (4) strong stiffness materials with maximum thickness, such as steel liners, should be attached to the rear surface of the last protective object.

Figure 19 plots the impact force-time history curves of a projectile vertically perforating five segmented targets at
TABLE 8: Contribution ratio of antiperforation performance with each part of segmented targets.

\begin{tabular}{lcccc}
\hline $\begin{array}{l}\text { Steel liner } \\
\text { layout }\end{array}$ & $\begin{array}{c}\text { Front steel } \\
\text { liner (\%) }\end{array}$ & $\begin{array}{c}1 \text { st } \\
\text { concrete } \\
(\%)\end{array}$ & $\begin{array}{c}\text { 2nd } \\
\text { concrete } \\
(\%)\end{array}$ & $\begin{array}{c}\text { Rear steel } \\
\text { liner }(\%)\end{array}$ \\
\hline $3-0-0-0$ & 9.95 & 37.21 & 52.84 & - \\
$2-0-0-1$ & 4.37 & 39.73 & 50.74 & 5.16 \\
$1.5-0-0-1.5$ & 3.18 & 35.09 & 55.22 & 6.51 \\
$1-0-0-2$ & 2.82 & 36.62 & 53.64 & 6.92 \\
$0-0-0-3$ & - & 41.26 & 50.67 & 8.07 \\
\hline
\end{tabular}

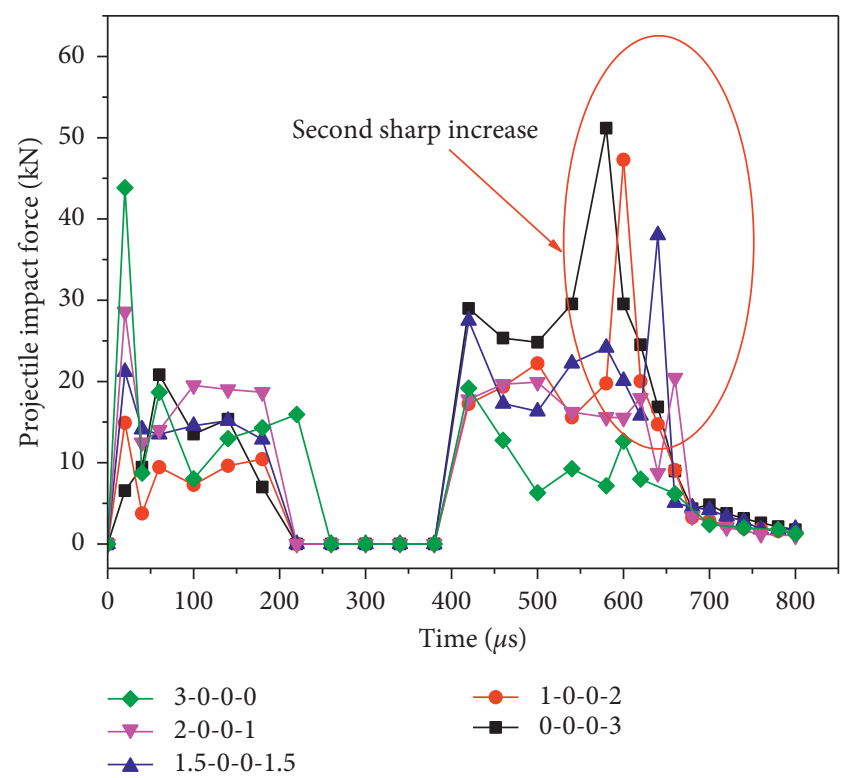

FIgURE 19: Impact force-time curves of projectile perforating segmented targets with different steel liner layouts.

$317 \mathrm{~m} / \mathrm{s}$. As mentioned above, whether monolithic or segmented targets, the projectile impact force was more influenced by the contact stiffness than that by the impact velocity during middle- or low-speed perforations. Figure 20 reveals the perforation process of segmented targets with different steel liner layouts. During the initial penetration stage, the concrete is extruded rapidly by the rigid projectile while the steel liner bulges upward. Unlike the monolithic targets, only a stable tunnel appears during the perforation of the first target under different working conditions except $0-0-0-3$, which is different from the real situation. This probably happens because the failure criterion of elements in this section is the same as that of the monolithic target; since the target structure has been changed, the original failure criterion may not be fully applicable, leading to a failure in the front crater formation under other working conditions. However, the aim of this paper, which is studying how the steel liner layout influences the perforation resistance of segmented targets, has been achieved. As regards the middle and terminal penetration stages, the penetration damage mechanism is similar to that of monolithic targets when the second segment is perforated by the projectile. 


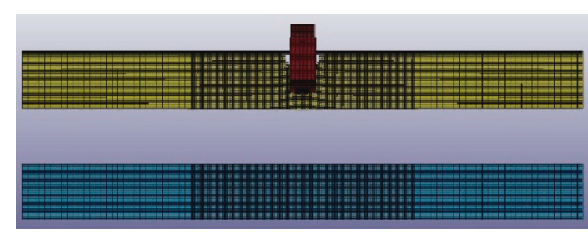

(a)

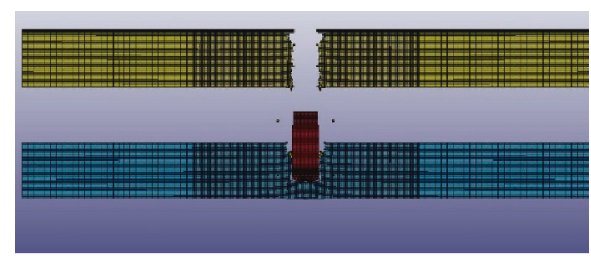

(c)

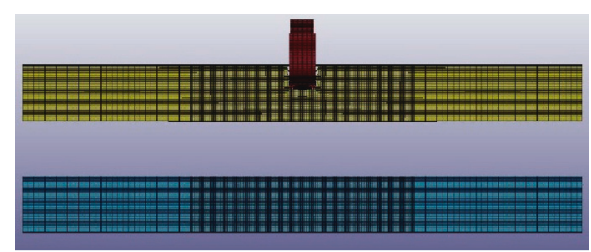

(e)

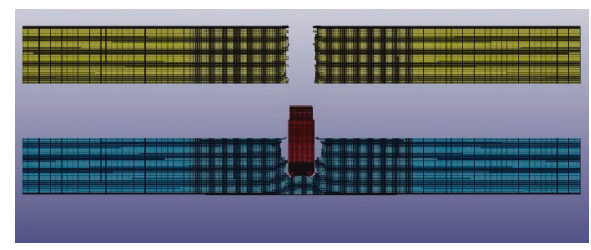

(g)

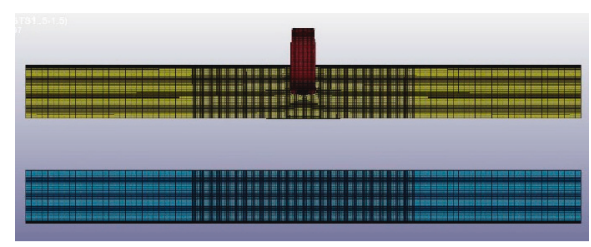

(i)

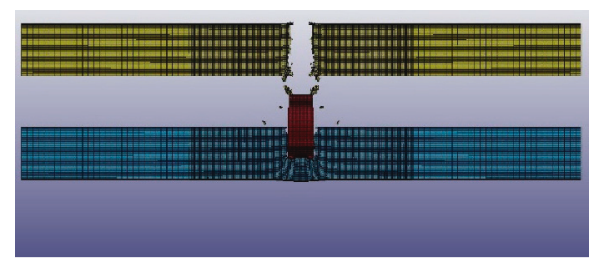

(k)

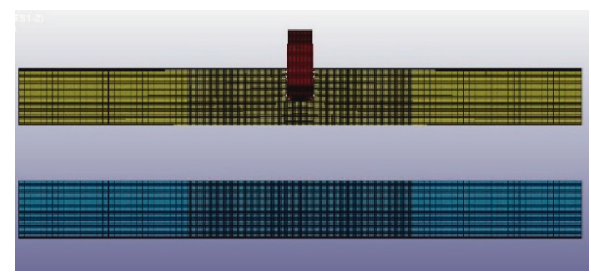

(m)

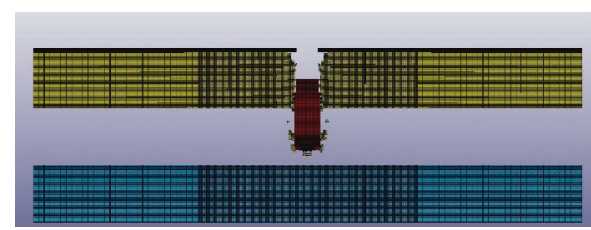

(b)

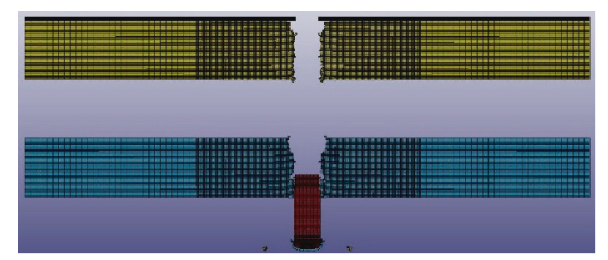

(d)

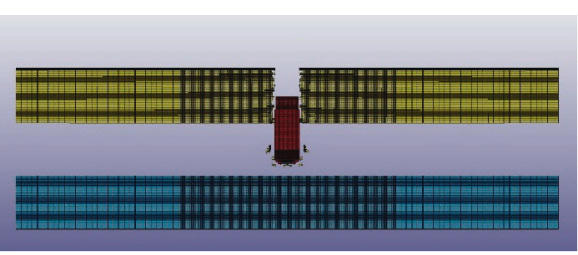

(f)

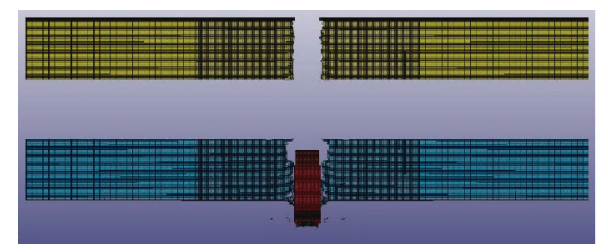

(h)

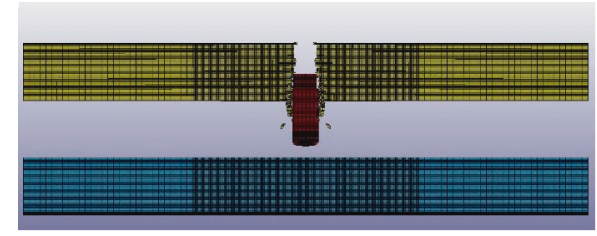

(j)

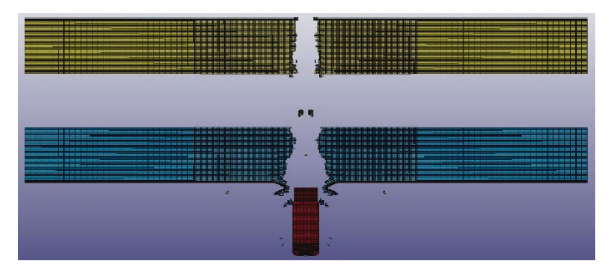

(1)

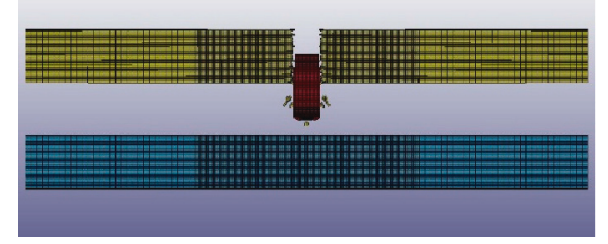

(n)

Figure 20: Continued. 


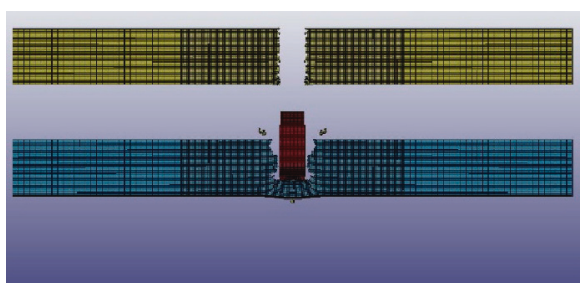

(o)

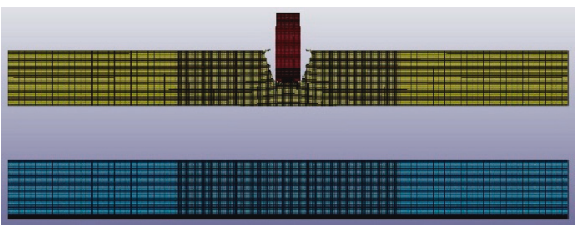

(q)

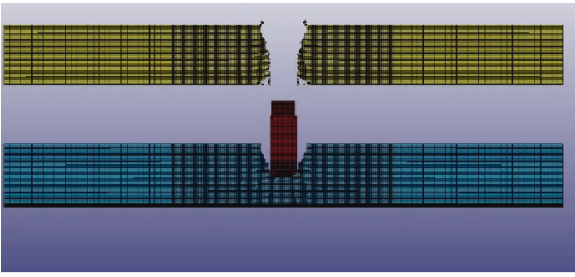

(s)

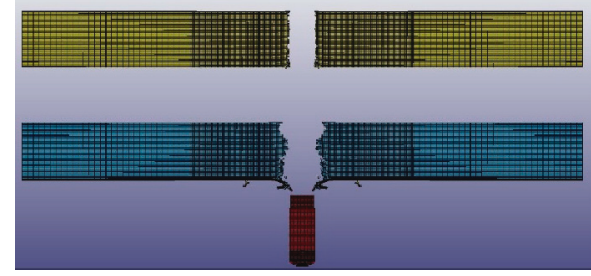

(p)

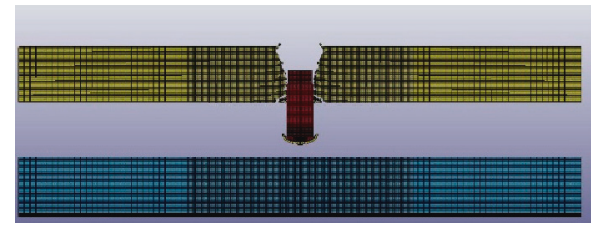

(r)

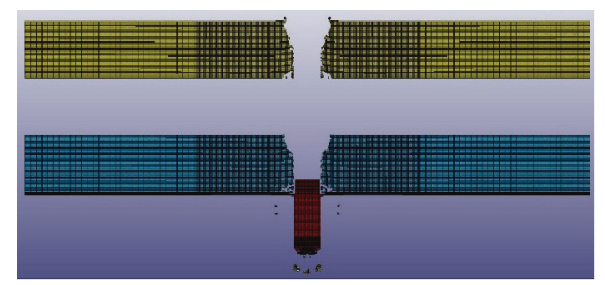

(t)

Figure 20: Perforation process of segmented targets with different steel liner layouts (1/2): (a) $140 \mu$ s (3-0-0-0); (b) 340 $\mu$ s (3-0-0-0); (c) $540 \mu \mathrm{s}$ (3-0-0-0); (d) $820 \mu \mathrm{s}$ (3-0-0-0); (e) $80 \mu \mathrm{s} \mathrm{(2-0-0-1);} \mathrm{(f)} 340 \mu \mathrm{s}(2-0-0-1)$; (g) $540 \mu \mathrm{s}(2-0-0-1)$; (h) $740 \mu \mathrm{s}(2-0-0-1)$; (i) $100 \mu \mathrm{s}(1.5-0-0-$ 1.5); (j) $340 \mu \mathrm{s}$ (1.5-0-0-1.5); (k) $520 \mu \mathrm{s}$ (1.5-0-0-1.5); (l) $820 \mu \mathrm{s} \mathrm{(1.5-0-0-1.5).} \mathrm{Perforation} \mathrm{process} \mathrm{of} \mathrm{segmented} \mathrm{targets} \mathrm{with} \mathrm{different} \mathrm{steel}$ liner layouts (2/2): (m) $100 \mu \mathrm{s}(1-0-0-2) ;(\mathrm{n}) 320 \mu \mathrm{s}$ (1-0-0-2); (o) $540 \mu \mathrm{s}(1-0-0-2)$; (p) $840 \mu \mathrm{s}(1-0-0-2)$; (q) $100 \mu \mathrm{s}(0-0-0-3)$; (r) 300 $\mathrm{s}$ (0-0-03); (s) $460 \mu \mathrm{s}(0-0-0-3)$; (t) $800 \mu \mathrm{s}(0-0-0-3)$.

\section{Conclusions}

The formula of residual velocity as well as $E_{\mathrm{r}} / E_{0}$ for composite targets with a rear steel liner was derived. Both monolithic and segmented concrete targets with a $3 \mathrm{~mm}$ steel liner were analyzed to determine how the steel liner layout affected their perforation resistance according to five working conditions established by ANSYS/LS-DYNA. The following main conclusions were drawn:

(1) Based on the conservation of kinetic energy, the residual velocity formula for a projectile perforating concrete targets with a rear steel liner was proposed and verified for the first time. A velocity reduction coefficient of 0.15 allows a more accurate prediction of the residual velocity so that the derived $E_{\mathrm{r}} / E_{0}$ can be used to evaluate the perforation resistance of composite targets with a rear steel liner.

(2) For monolithic and segmented concrete targets with steel liners, the formation of "bulges" and rear craters can be "delayed" by thickening the rear steel liner. When a $3 \mathrm{~mm}$ steel liner is moved from the front surface to the rear one of the target, the target perforation resistance is gradually increased, where $0-3$ is about $10 \%$ higher than $3-0$ and $0-0-0-3$ is about $13 \%$ higher than 3-0-0-0. However, the perforation resistance of segmented concrete targets with a steel liner is inferior to the analogous monolithic ones, which is reduced by $10 \%-16 \%$ under similar conditions (e.g., 3-0 and 3-0-0-0).

(3) During middle- and low-speed perforations, the projectile impact force is more influenced by contact stiffness than impact velocity, whether the concrete target with a steel liner is monolithic or segmented. The secondary peak value of the impact force is increased with the rear steel liner becoming thick. As a result, the contact stiffness should be enhanced as much as possible in the protective structures with limited space, such as steel liners, ceramic/fiber boards, and ceramic/aluminum alloy boards, which provide a better impact resistance.

(4) With regard to segmented targets, the perforation resistance of the 2 nd target is better than the 1 st target under five working conditions, consuming about $10 \%-20 \%$ more projectile kinetic energy.

(5) The following optimal design measures for segmented protective structures can be formulated: (i) the minimum thickness of shock stress homogenization should be ensured in protective structures; (ii) the interval of each protective object should be minimized to reduce the damage and deformation recovery of the projectile; (iii) a protective object with a great strength and thickness should be placed at the end; and (iv) strong stiffness materials with maximum thickness, such as steel liners, should be 
attached to the rear surface of the last protective object.

\section{Data Availability}

The data used to support the findings of this study are available from the corresponding author upon request.

\section{Conflicts of Interest}

The authors declare there are no conflicts of interest regarding the publication of this paper.

\section{Authors' Contributions}

Yi Cheng carried out the theoretical analysis and numerical simulation. Zhimin Xiao reviewed this paper and made some constructive amendments. Yuan Zhang edited and wrote the research paper.

\section{Acknowledgments}

This research was supported by the National Natural Science Foundation of China (nos. 51874118, 51174076, and 51044003) and Fundamental Research Funds for the Central Universities (no. KYCX18-0567).

\section{References}

[1] R. P. Kennedy, "A review of procedures for the analysis and design of concrete structures to resist missile impact effects," Nuclear Engineering and Design, vol. 37, no. 2, pp. 183-203, 1976.

[2] Y. Wang, "The local damage and the design evaluation formulas of reinforced-concrete plates subjected to the impact of projectiles," Chinese Journal of Nuclearence \& Engineering, vol. 14, no. 3, pp. 203-212, 1994.

[3] G. G. Corbett, S. R. Reid, and W. Johnson, "Impact loading of plates and shells by free-flying projectiles: a review," International Journal of Impact Engineering, vol. 18, no. 2, pp. 141-230, 1996.

[4] M. Beppu, C. Abadie, J. Takahashi, and A. Ogawa, "Effects of short fiber reinforcement on the local damage of concrete plates under high velocity impact loading," Applied Mechanics and Materials, vol. 82, no. 2, pp. 241-246, 2011.

[5] M. Rodríguez-Millán, A. Díaz-Álvarez, R. Bernier, M. H. Miguélez, and J. A. Loya, "Experimental and numerical analysis of conical projectile impact on inconel 718 plates," Metals, vol. 9, no. 6, p. 638, 2019.

[6] J. Gao, Z. Chen, W.-T. Wu, and X. Li, "Numerical investigations on the water entry of cylindrical projectiles with different initial conditions," Applied Sciences, vol. 9, no. 9, p. 1858, 2019.

[7] J. Mizuno, N. Koshika, Y. Sawamoto, N. Niwa, A. Suzuki, and T. Yamashita, "Investigation on impact resistance of steel plate reinforced concrete barriers against aircraft impact. Pt.1: test program and results," in Proceedings of the International Conference on Structural Mechanics in Reactor Technology, pp. 2566-2579, Beijing, China, August 2005.

[8] G. B. Dor, A. Dubinsky, and T. Elperin, "Optimization of reinforced concrete panels with rear face steel liner under impact loading," Mechanics Based Design of Structures and Machines, vol. 37, no. 4, pp. 503-512, 2009.
[9] X. Zhu, G. Lin, R. Pan et al., "Sensitivity analysis for impact resistance of steel plate concrete walls based on force vs. timehistory analysis," Explosion \& Shock Waves, vol. 36, no. 5, pp. 670-679, 2016.

[10] T. A. Walter and A. M. Wolde-Tinsae, "Turbine missile perforation of reinforced concrete," Journal of Structural Engineering, vol. 110, no. 10, pp. 2439-2455, 1984.

[11] M. Abdel-Kader and A. Fouda, "Mild steel plates impacted by hard projectiles," Journal of Constructional Steel Research, vol. 99, no. 99, pp. 57-71, 2014.

[12] M. Abdel-Kader and A. Fouda, "Equivalent concrete thickness for perforation of mild steel plates," Journal of Constructional Steel Research, vol. 135, pp. 213-229, 2017.

[13] J. C. Bruhl, A. H. Varma, and W. H. Johnson, "Design of composite SC walls to prevent perforation from missile impact," International Journal of Impact Engineering, vol. 75, pp. 75-87, 2015.

[14] H. Grisaro and A. N. Dancygier, "Assessment of the perforation limit of a composite RC barrier with a rear steel liner to impact of a non-deforming projectile," International Journal of Impact Engineering, vol. 64, no. 2, pp. 122-136, 2014.

[15] Q. Chang, S. Yang, D. Wang et al., "Ballistic resistance of honeycomb sandwich panels under in-plane high-velocity impact," The Scientific World Journal, vol. 2013, Article ID 892781, 20 pages, 2013.

[16] T. Zhan, J. Li, S. Lv et al., "Residual velocity for the truncated ogival-nose projectile into stiffened plates," Ships \& Offshore Structures, vol. 11, no. 6, pp. 636-644, 2015.

[17] C. Yi, J. Liu, X.-F. Liu et al., "Theoretical and numerical analysis on anti-penetration property of reinforced concrete target under normal penetration," Science Technology and Engineering, vol. 19, no. 1, pp. 97-103, 2019.

[18] L. Ding, W. Tang, X. Ran, Z. Fan, and W. Chen, "Theoretical model of the axial residual velocity of PELE projectiles penetrating thin metal targets," Symmetry, vol. 11, no. 6, p. 776, 2019.

[19] Y. Peng, H. Wu, Q. Fang, J. Z. Liu, and Z. M. Gong, "Residual velocities of projectiles after normally perforating the thin ultra-high performance steel fiber reinforced concrete slabs," International Journal of Impact Engineering, vol. 97, pp. 1-9, 2016.

[20] Y. Peng, H. Wu, Q. Fang, Z. M. Gong, and X. Z. Kong, "A note on the deep penetration and perforation of hard projectiles into thick targets," International Journal of Impact Engineering, vol. 85, pp. 37-44, 2015.

[21] C. H. Chen, X. Zhu, H. L. Hou, X.-B. Tian, and X.-L. Shen, “A new analytical model for the low-velocity perforation of thin steel plates by hemispherical-nosed projectiles," Defence Technology, vol. 13, no. 5, pp. 7-17, 2017.

[22] H. Grisaro and A. N. Dancygier, "A modified energy method to assess the residual velocity of non-deforming projectiles that perforate concrete barriers," International Journal of Protective Structures, vol. 5, no. 3, pp. 307-321, 2014.

[23] P. Barr, Guidelines for the Design and Assessment of Concrete Structures Subjected to Impact, United Kingdom Atomic Energy Authority Safety and Reliability Directorate, Culcheth, UK, 1990.

[24] H. Tsubota, Y. Koshika, H. Morikawa et al., "Quantitative studies in impact resistance of reinforced concrete panels with steel liners under impact loading, part 1: scaled model impact tests," in Proceedings of the 12th International Conference on International Association for Structural Mechanics in Reactor Technology (SMIRT), pp. 169-173, Stuttgart, Germany, August 1993. 
[25] Z. Rosenberg and E. Dekel, "On the deep penetration and plate perforation by rigid projectiles," International Journal of Solids and Structures, vol. 46, no. 24, pp. 4169-4180, 2009.

[26] Z. Rosenberg and E. Dekel, "Revisiting the perforation of ductile plates by sharp-nosed rigid projectiles," International Journal of Solids and Structures, vol. 47, no. 22-23, pp. 3022-3033, 2010.

[27] I. Kojima, "An experimental study on local behavior of reinforced concrete slabs to missile impact," Nuclear Engineering \& Design, vol. 130, no. 2, pp. 121-132, 1991.

[28] A. M. Remennikov and S. Y. Kong, "Numerical simulation and validation of impact response of axially-restrained steel-concrete-steel sandwich panels," Composite Structures, vol. 94, no. 12, pp. 3546-3555, 2012.

[29] M. Abdel-Kader and A. Fouda, "Effect of reinforcement on the response of concrete panels to impact of hard projectiles," International Journal of Impact Engineering, vol. 63, pp. 1-17, 2014.

[30] H. Wu, Q. Fang, Y. Peng, Z. M. Gong, and X. Z. Kong, "Hard projectile perforation on the monolithic and segmented RC panels with a rear steel liner," International Journal of Impact Engineering, vol. 76, pp. 232-250, 2015.

[31] J. Jing, "An investigation on equivalence relation between the side structure of vessels and even target plates," Journal of Ballistics, vol. 12, no. 1, pp. 83-87, 2000.

[32] G. I. Taylor, "The formation and enlargement of a circular hole in a thin plastic sheet," The Quarterly Journal of Mechanics and Applied Mathematics, vol. 1, no. 1, pp. 103-124, 1948.

[33] A. I. O. Zaid, A. El-Kalay, and F. W. Travis, "An examination of the perforation of a mild steel plate by a flat-ended cylindrical projectile," International Journal of Mechanical Sciences, vol. 15, no. 2, pp. 129-143, 1973.

[34] C. M. Song and M. Y. Wang, "Study on perforation coefficient of concrete plate impacted by rigid projectiles," Journal of Vibration \& Shock, vol. 27, no. 11, pp. 101-104, 2008.

[35] G. Ben-Dor, A. Dubinsky, and T. Elperin, "Empirical models for predicting protective properties of concrete shields against high-speed impact," Journal of Mechanics of Materials \& Structures, vol. 8, no. 2-4, pp. 199-232, 2013.

[36] N. D. Avraham, "Rear face damage of normal and highstrength concrete elements caused by hard projectile impact," ACI Structural Journal, vol. 95, no. 3, pp. 291-304, 1998.

[37] J. Li, Z. Lv, H. Zhang, and F. L. Huang, "Perforation experiments of concrete targets with residual velocity measurements," International Journal of Impact Engineering, vol. 57, no. 1, pp. 1-6, 2013.

[38] L. Hao-Kai, Study on Penetration Resistance of Steel PlateConcrete Composite Structures Based on Finite Element Method, Nanjing University of Science \& Technology, Nanjing, China, 2015. 


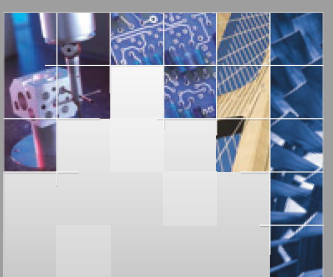

\section{Enfincering}
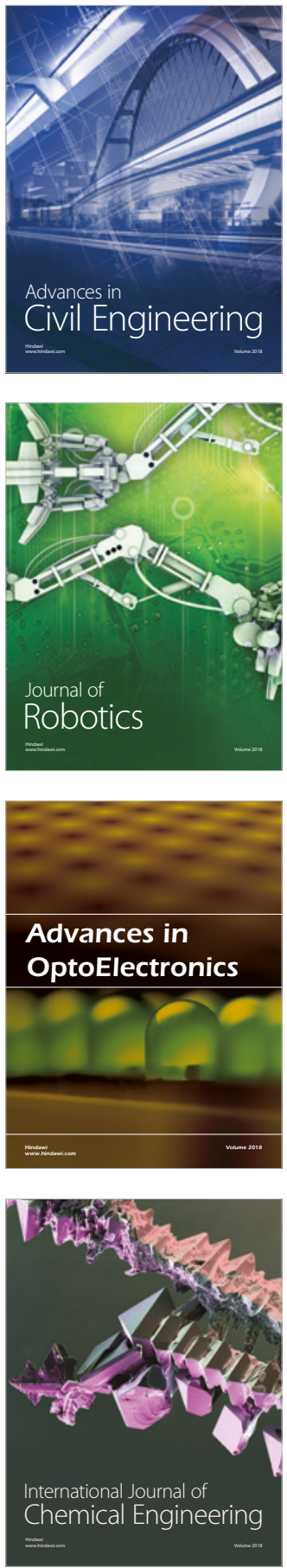

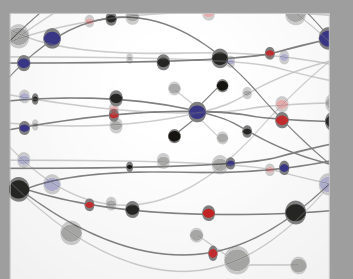

\section{Rotating \\ Machinery}

The Scientific World Journal

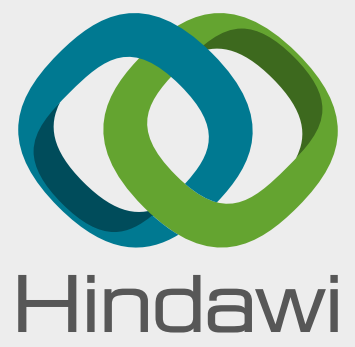

Submit your manuscripts at

www.hindawi.com
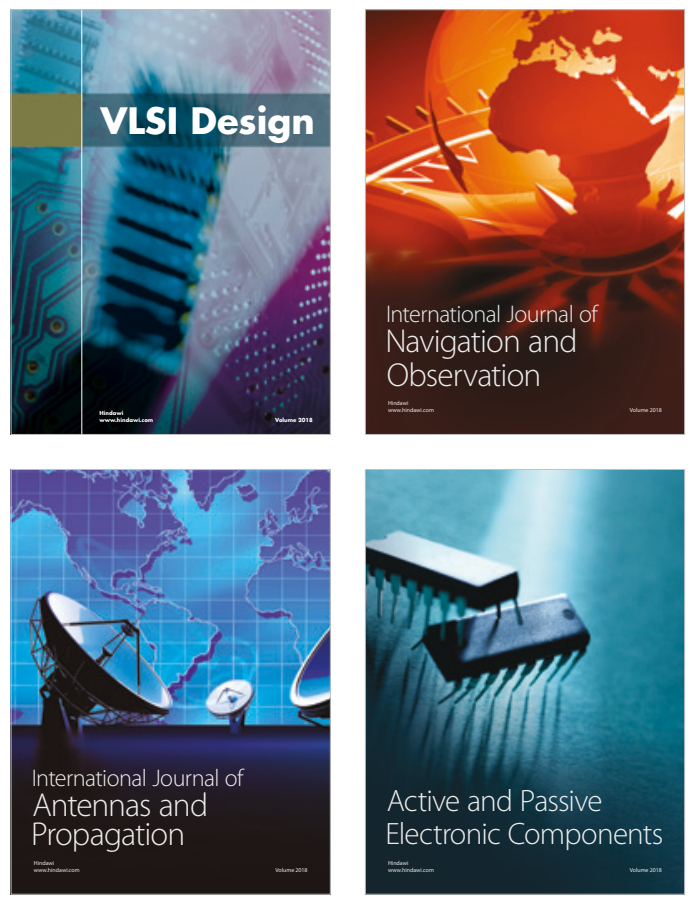
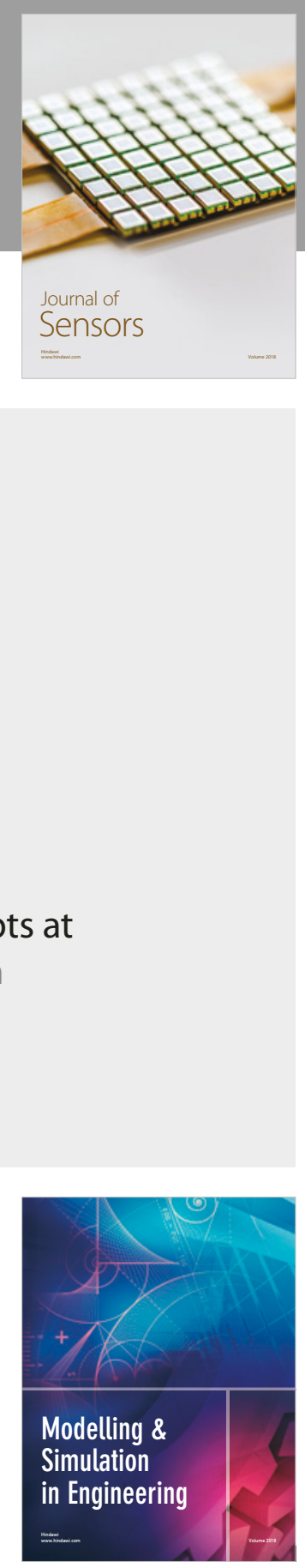

\section{Advances \\ Multimedia}
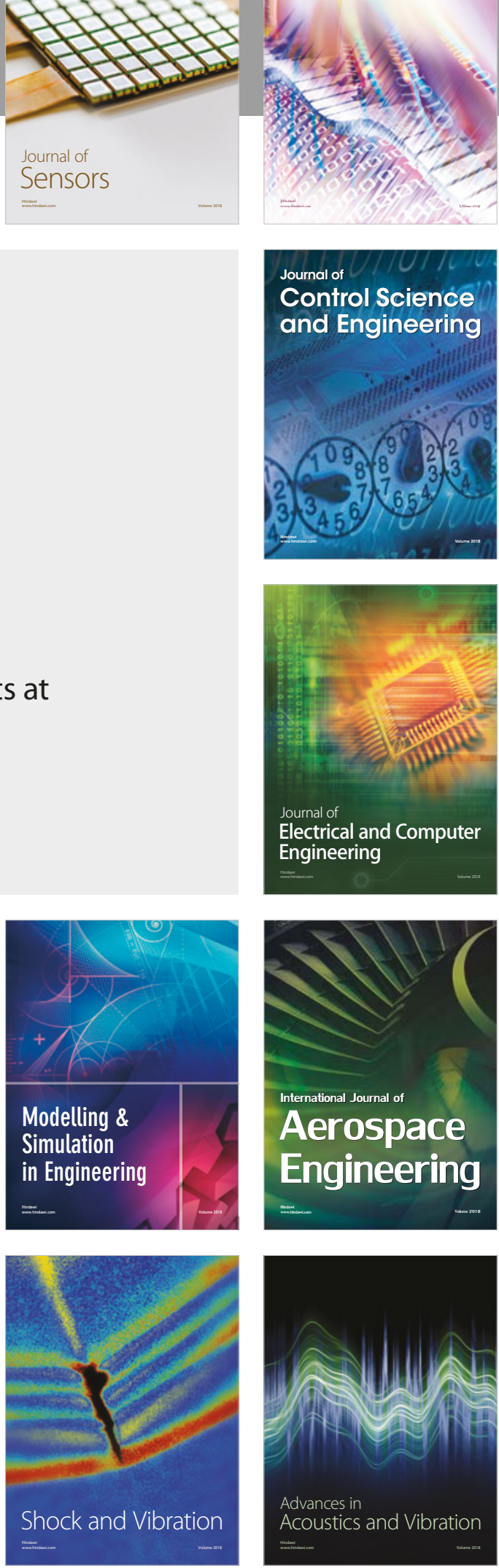